\title{
مشكلة البحث (Problematic)
}

\author{
المفهوم، ، الصياغة، الخصائص الخص
}

د.رقية بوسنان

أستاذ محاضر أ

جامعة الأمير عبد القادر / قسنطينة

\section{ملخص}

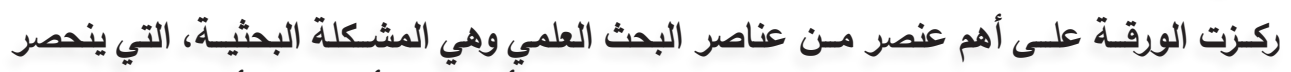

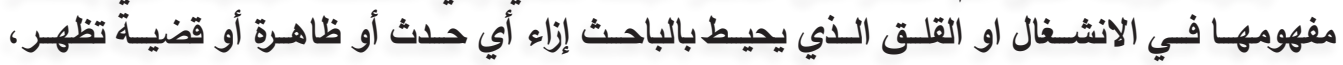

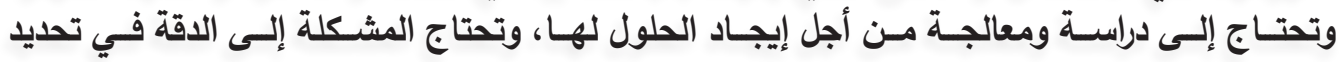

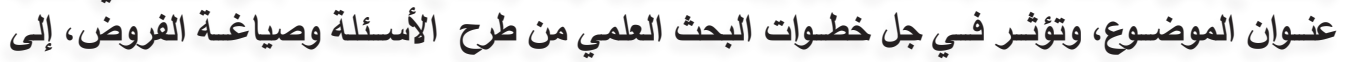

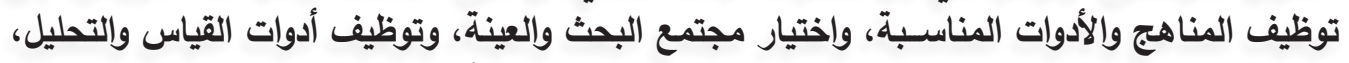

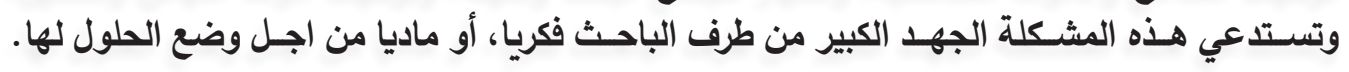
الكلمات المفتاحية: المشكلة، البحث العلمي، الصياغة، المنهجية.

Research Problem / Concept, Formation and Characteristics

Prof.: Ruqaya Businan

University Alameer Abdalkadir

Abstract

This paper focuses on the most important element of scientific research: the research problem which is confined to the concept of concern or concern surrounding the researcher about any event or phenomenon or issue paper and need to be studied and addressed in order to fine solutions for them, to influence the most scientific research steps from asking questions and formulating hypotheses, to employ suitable methods and tools to choose the research and sample community, to employ measurement and analysis tools. This problem calls for a great effort by the researcher intellectually or materially to develop solutions.

Key words: Problematic, scientific research, drafting, methodology

b_rokeia@yahoo.fr

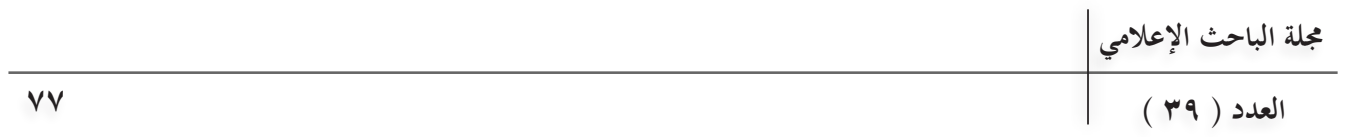




\section{مقدمة}

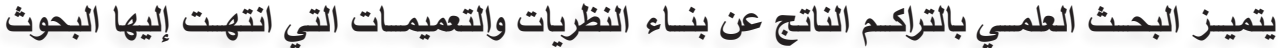

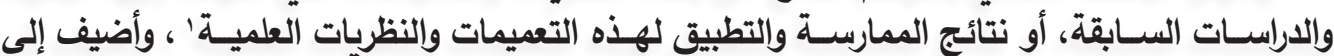

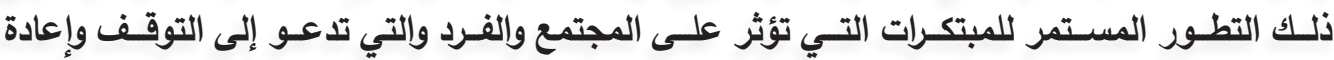
التفكيـر والتأليـف من جديد أو إضافـة الجديد.

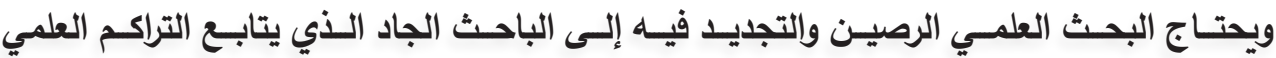

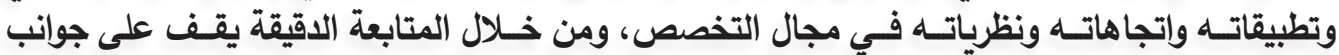

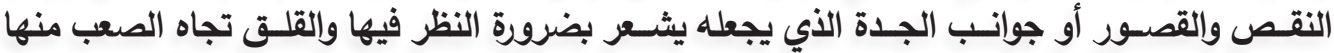

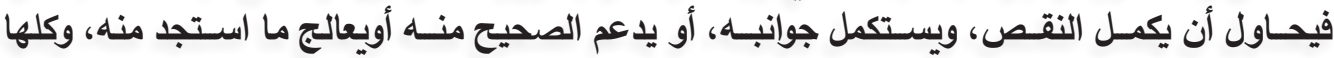

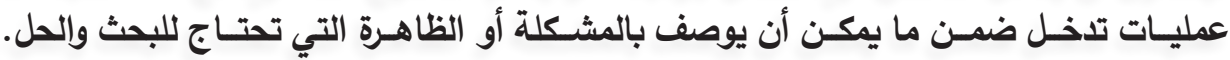
ويأتسي هـا العـرض للكتابة في عنصر مهم مسن عناصر البحث العلمي وهي المشـكلة التي طالما

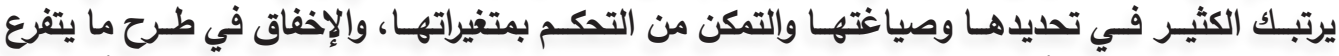

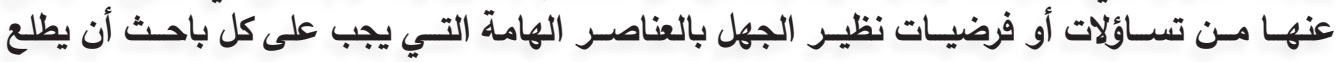

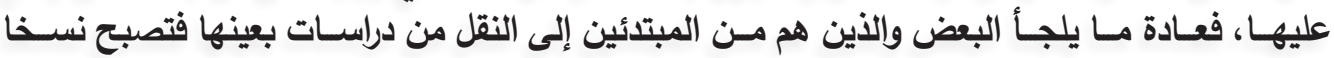

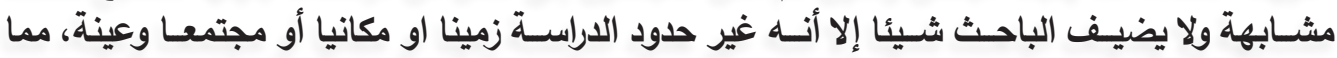

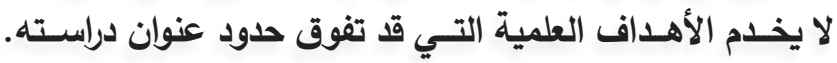

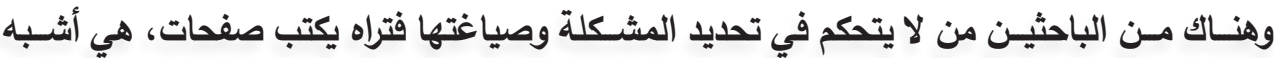

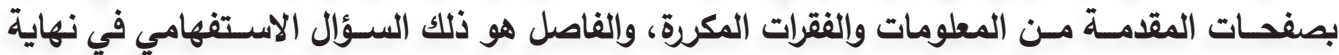

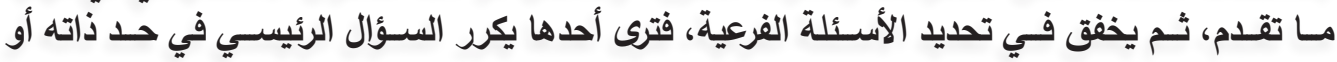

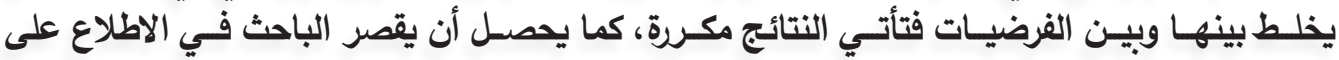

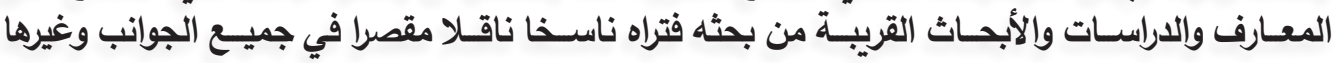
مـن المشـاكل التي يقع فيها الباحـث المبتدئ.

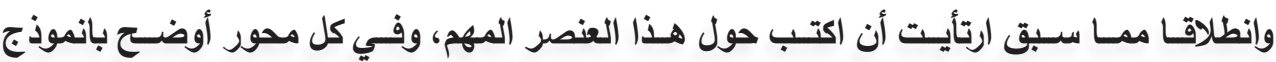

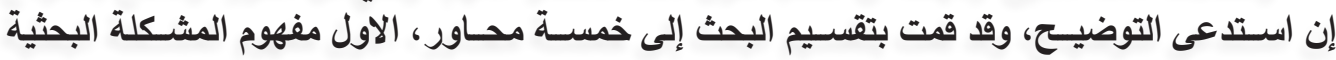

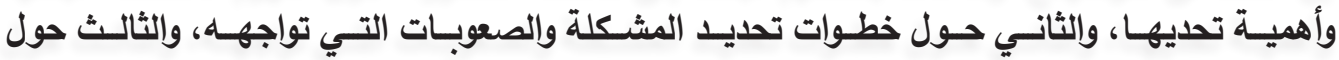

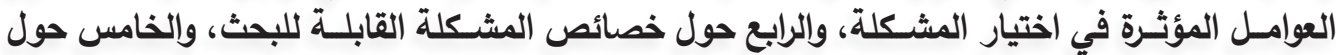

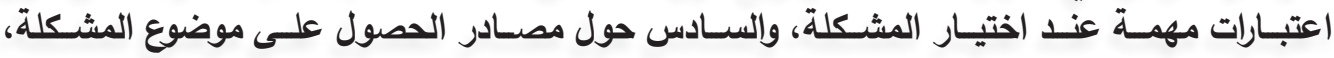

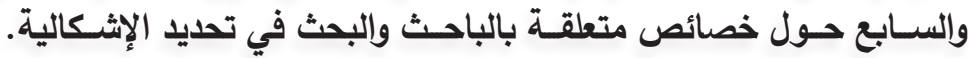




\section{أولا: مفهوم المشكلة البحثية وأهمية تحديدها.}

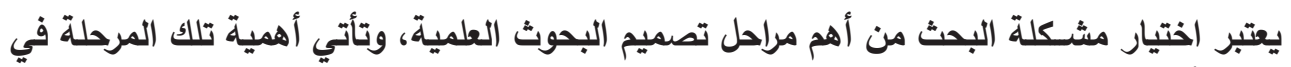

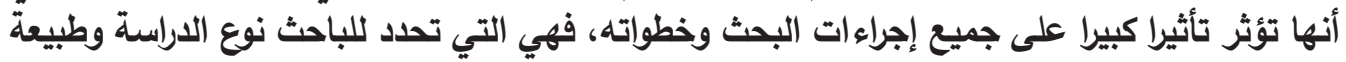

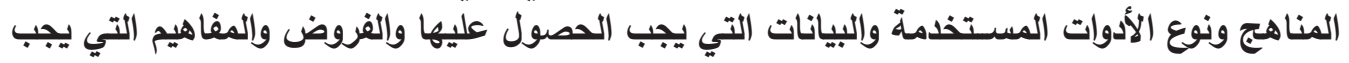

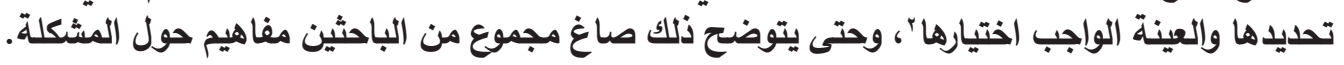

\section{ا-تعريف المشكلة}

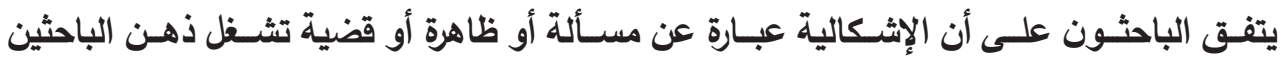

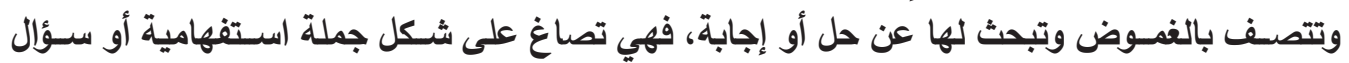

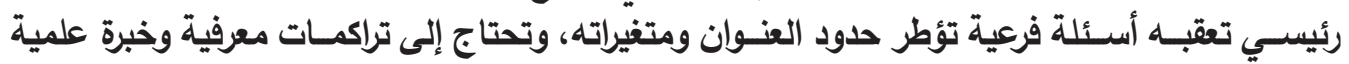

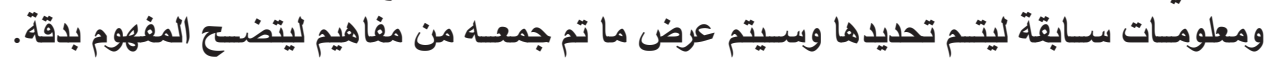

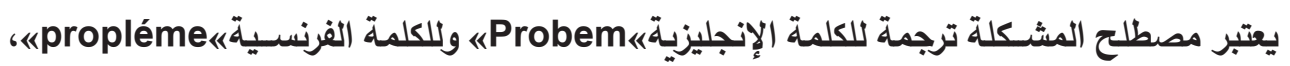

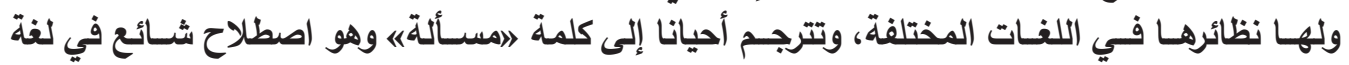

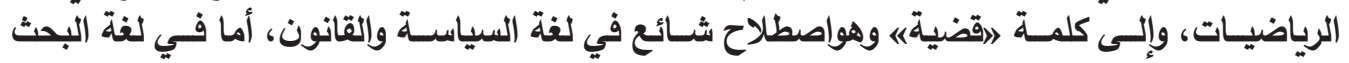

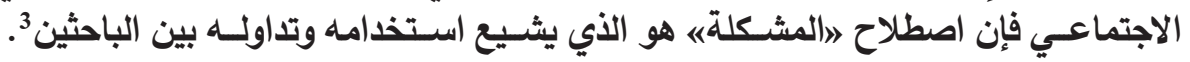

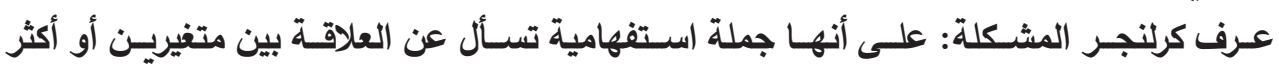

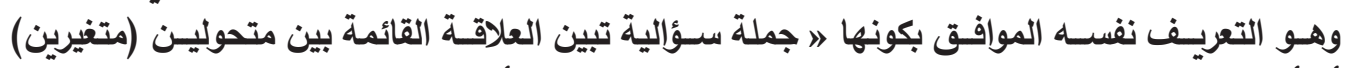

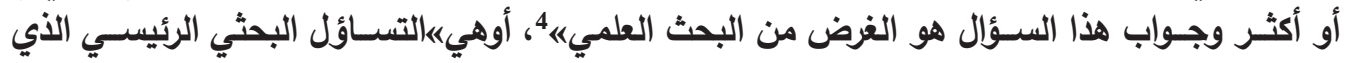

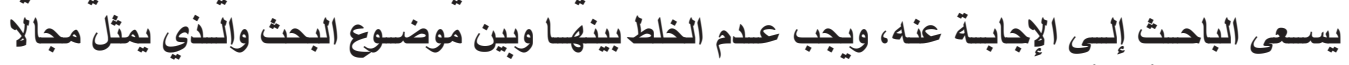

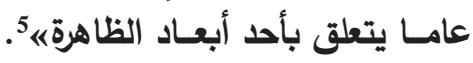

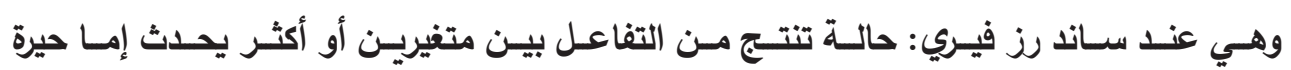

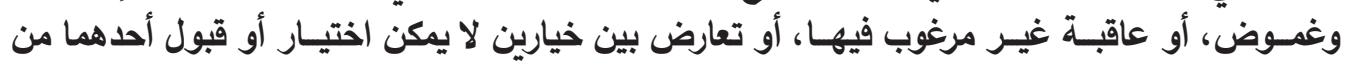

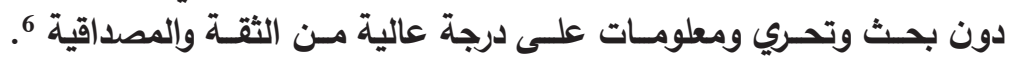

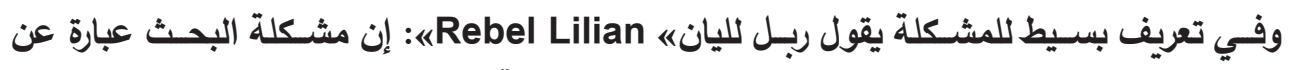

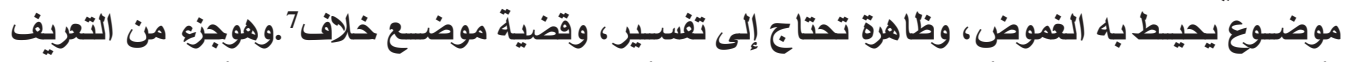

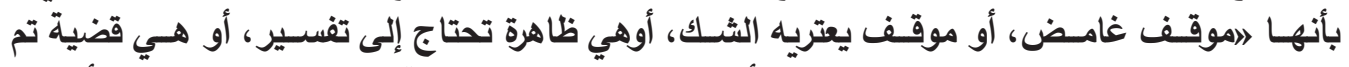

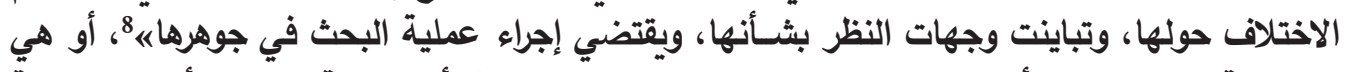

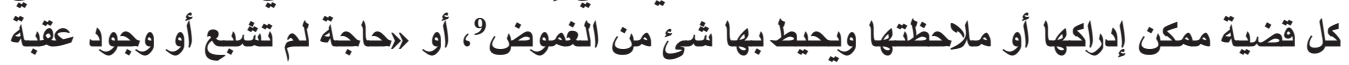

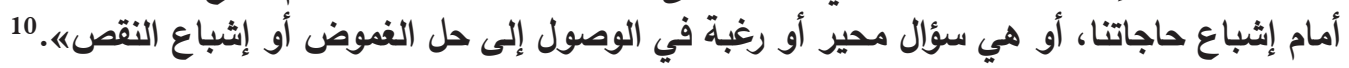

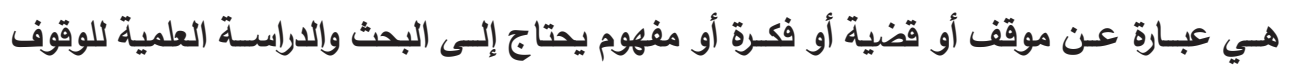

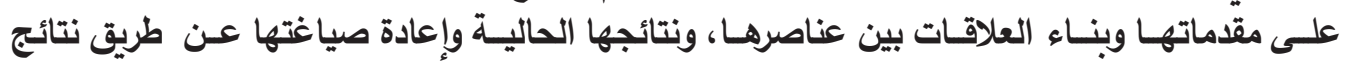

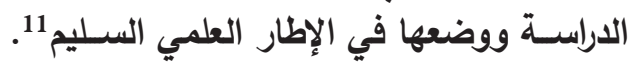




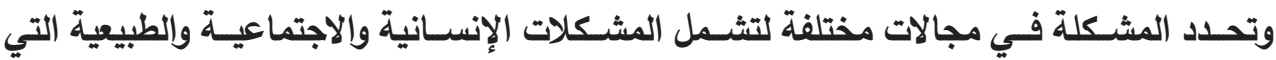

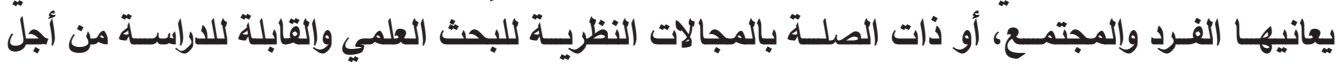

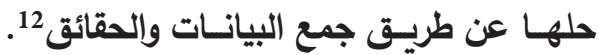

والمشـكلة عبـارة عـن الفرق الذي يحس به الباحث بين وضع الانطـلاق الذي يظهر فيه على فئل أنه

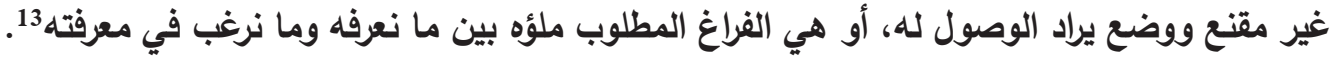

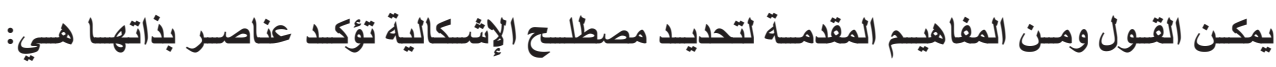
يوازي مفهوم المشكلة، مفهوم القضية، الموقف، الفكرة، الظاهرة. يصاحب الباحث إحساس بالقلق والتردد والمحاولة الجادة لمعالجة هذه المشكلة.

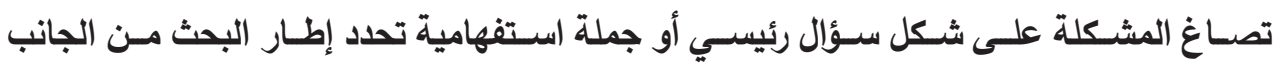
النظـي، والجانسب التطبيقي(الميدانسي والتحليلي)

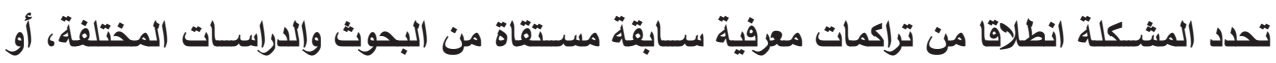
مـن الملاحظة الدقيقـة للظواهر الاجتماعية. يتطلب الإجابة عن المثكلة جهاً فكرياً ومادياً كبيرين.

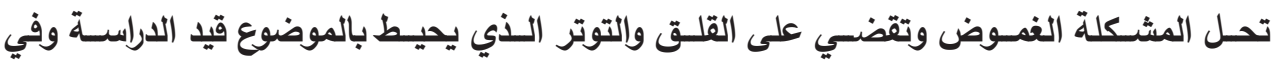
المجـالات المختلفة.

\section{r- أهمية تحديد (صياغة) المشكلة المئة}

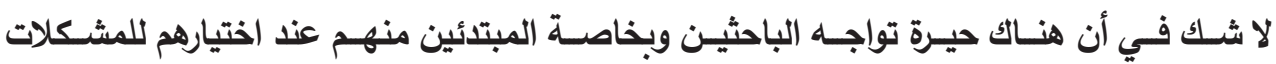

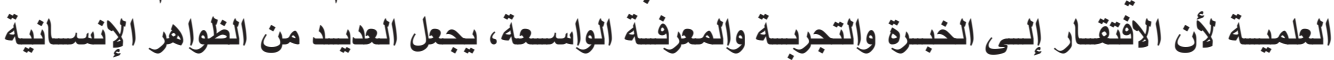

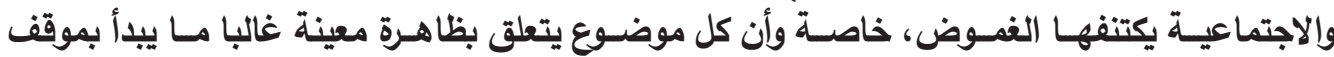

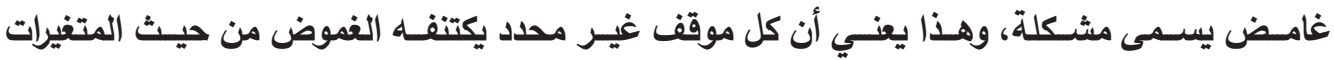

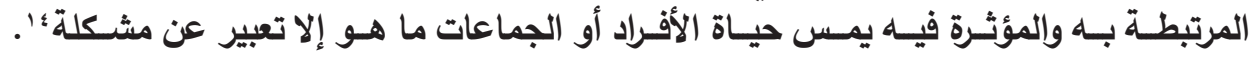

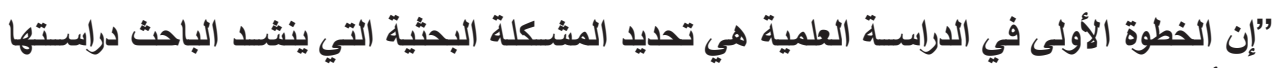

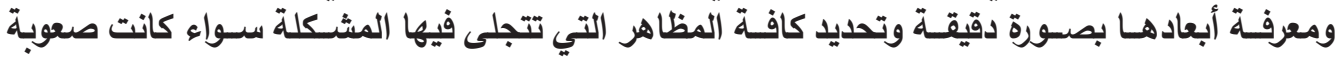

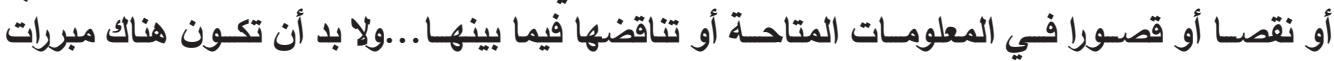

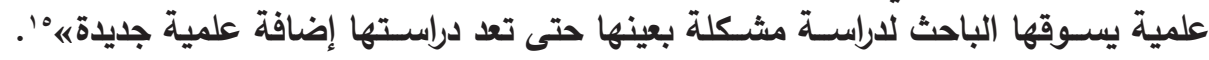

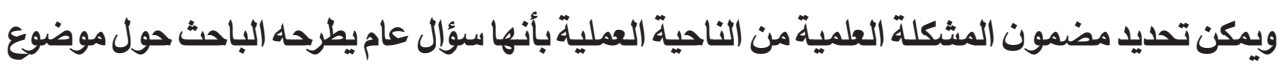

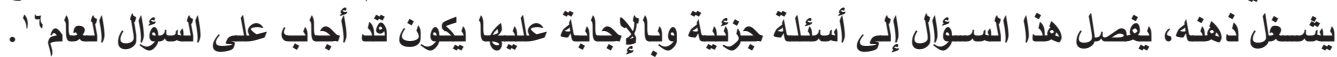

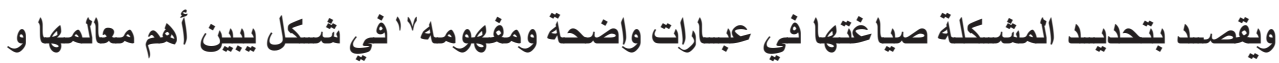

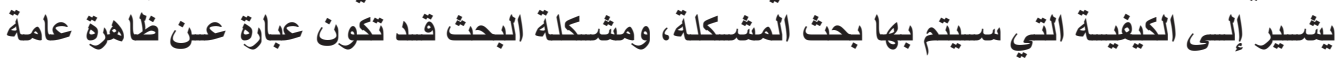

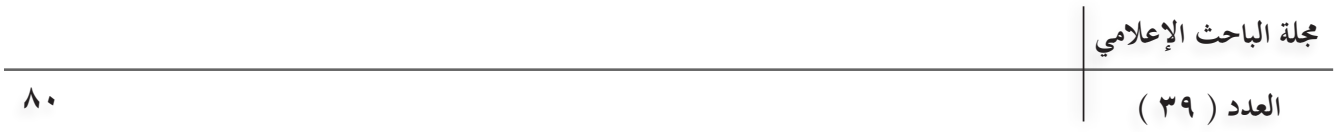


أو جـزء مـن ظاهرة وتثـــل حدود المشـكلة جميع جوانب الظاهـرة أو جوانب الجزء الذي سـيركز عليه الاهتمـام من الظاهرة.

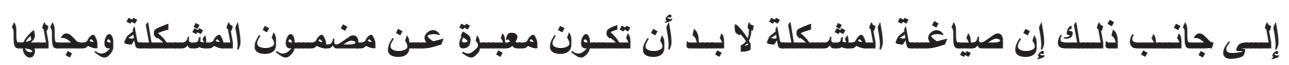

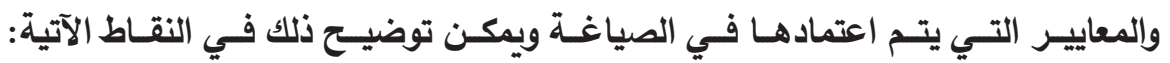

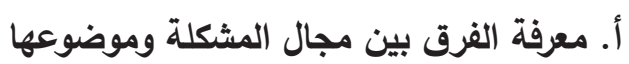

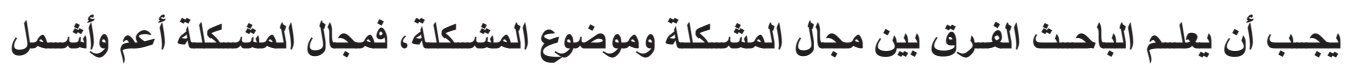

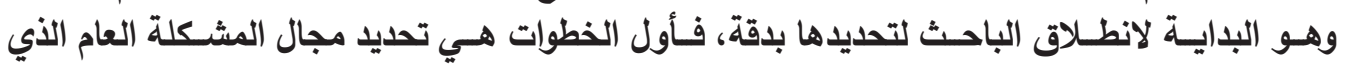

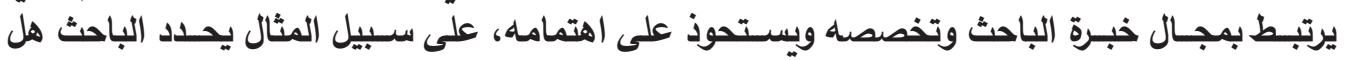

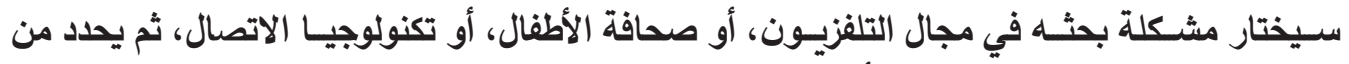

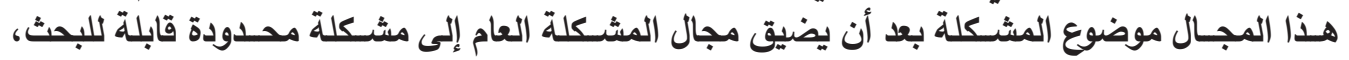

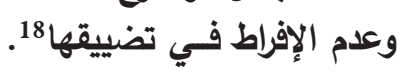

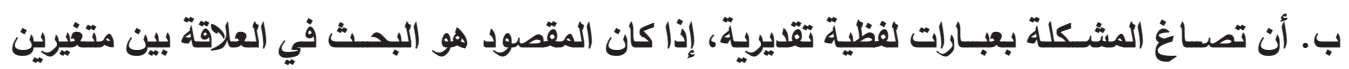

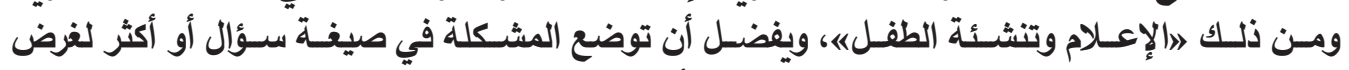

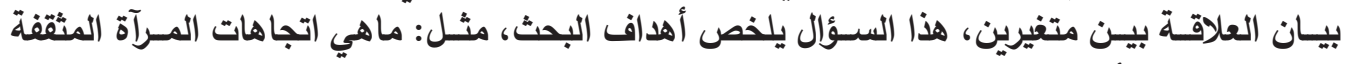

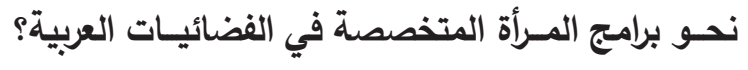

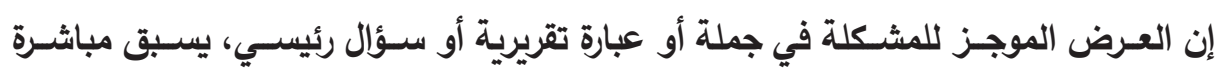

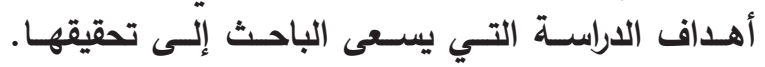
ج. اللجوء إلى معايير عدة عند صياغة المثكلة وتتمثل في:

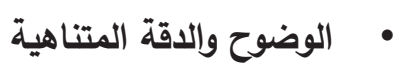

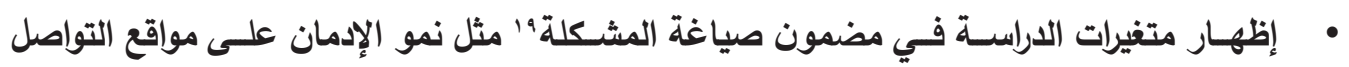
الاجتماعي يؤدي إلى ضعف التحصيل الدراسيسي.

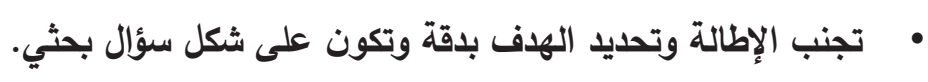

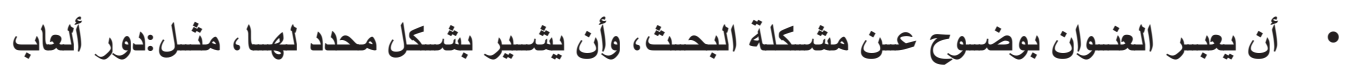

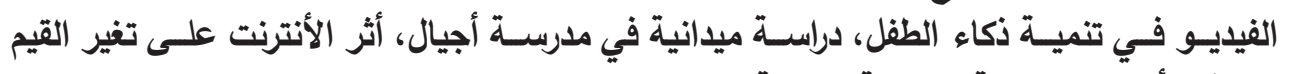

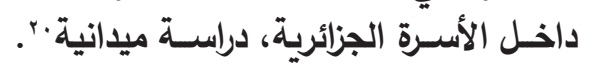

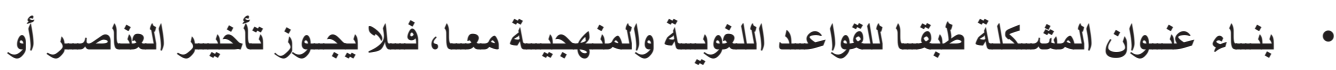

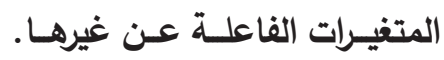
• الفصل في بناء العنوان بين ما يثير إلى العلاقات أو يثير إلى الأداء أو المجالات.

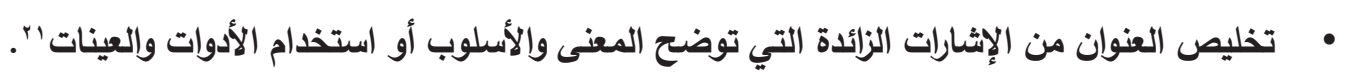

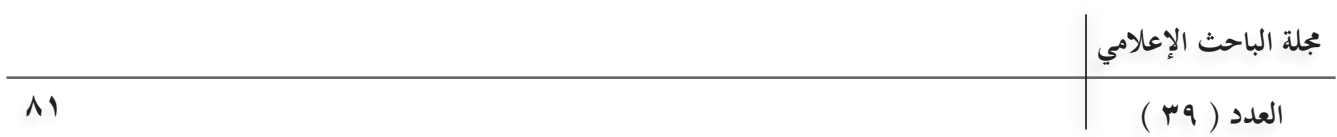


إن تحديد مثكلة البحث لايتوقف عند نقطة صياغة هذه الأخيرة في شكل سؤال وفقط، بل القيام أيضا

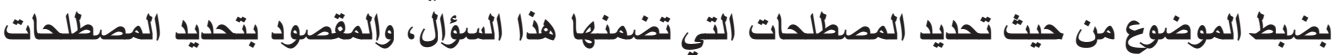

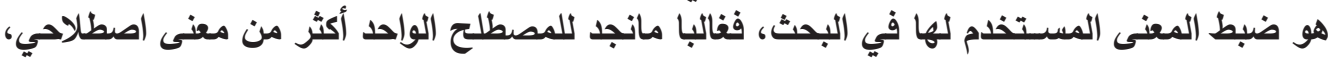

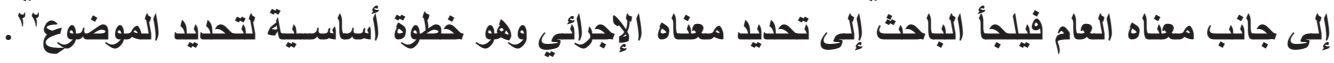

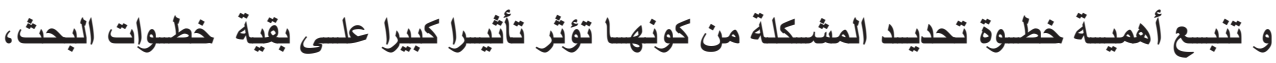

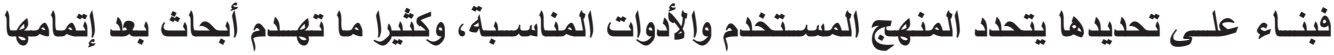

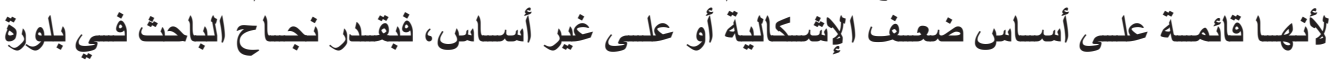

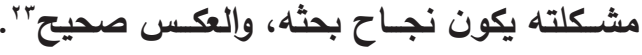

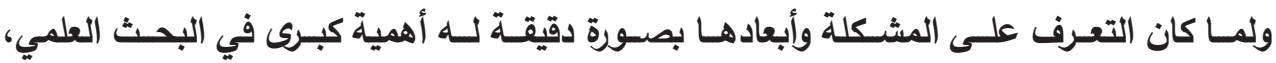

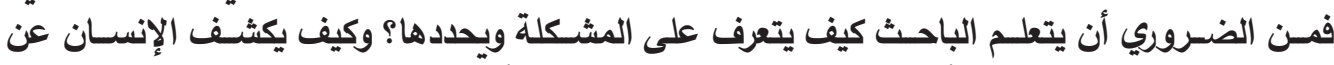

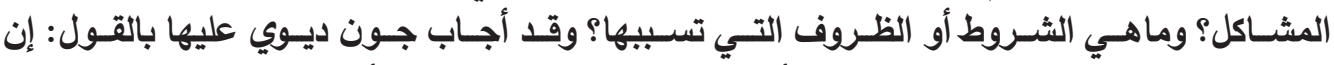

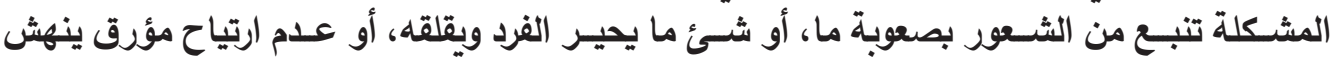

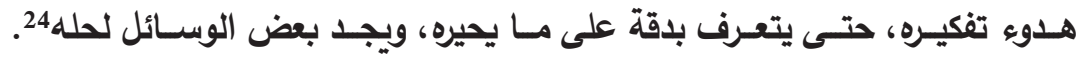

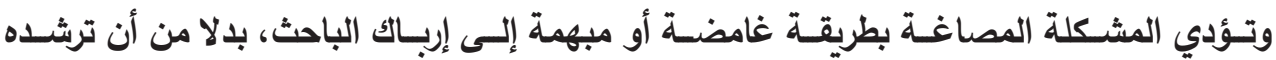

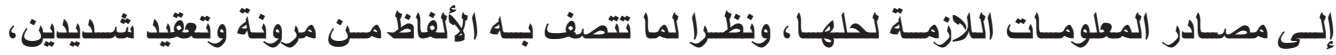

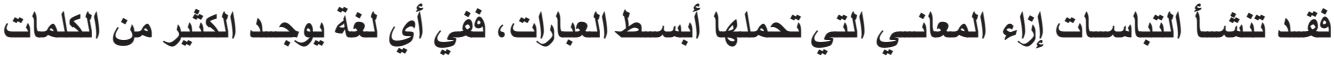

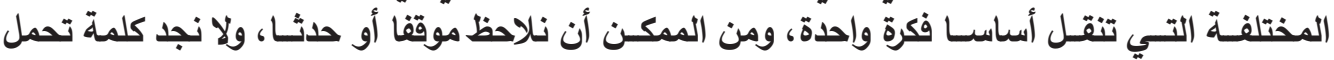

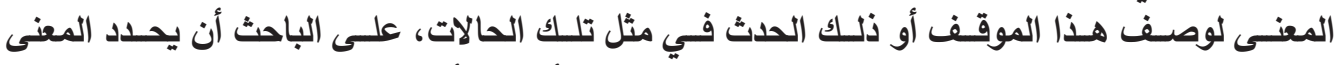

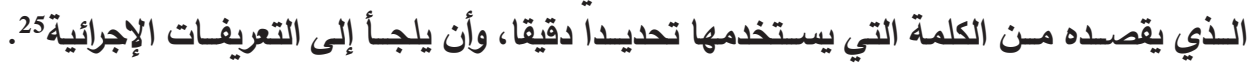

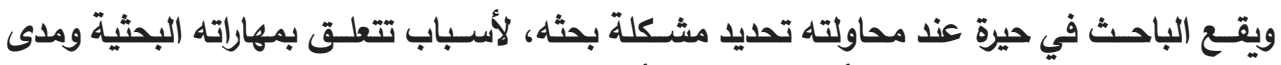

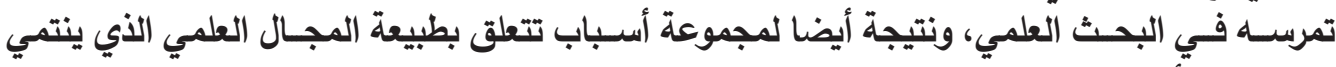

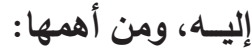

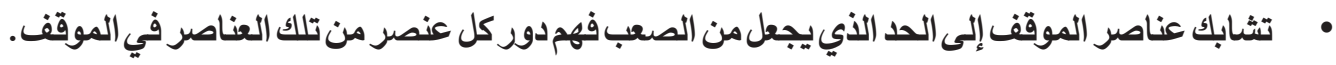

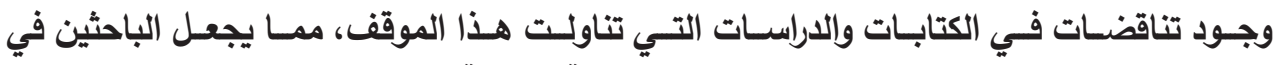

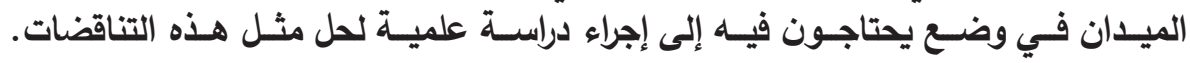

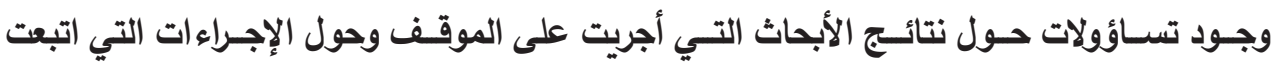

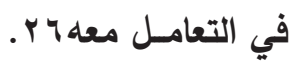
نموذّج لصياغة الإشكالية دراســة خاصـة اصصورة الولايـات المتحد الأمريكية في الصحافة العربية بعـد حرب الخليج الثالثةه.

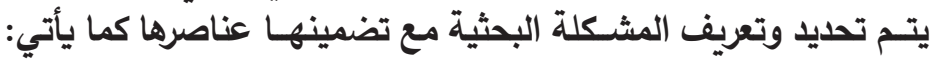




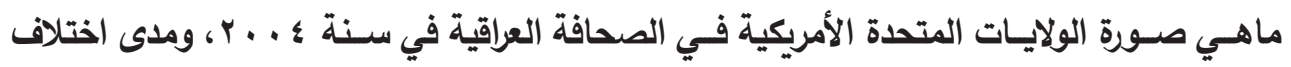
الصـورة بين الصحـف القومية والصحف الحزبيـة والصحف الحكومية؟؟.

$$
\text { يمكن أن نتعرف عن طريق هذه المشكلة على: }
$$

• المشكلة البحثية الرئيسية : توضيح صورة الولايات المتحدة الأمريكية في الصحافة العراقية.

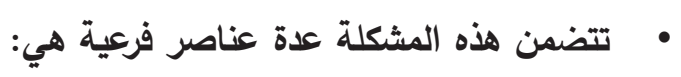

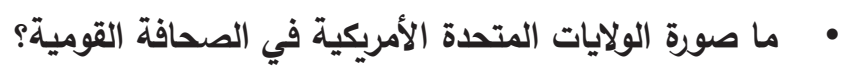

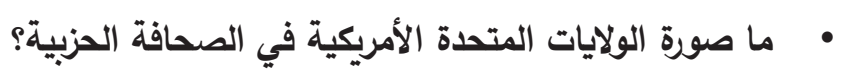

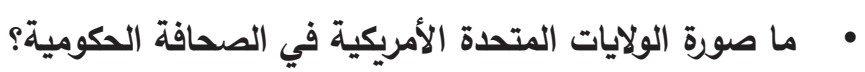

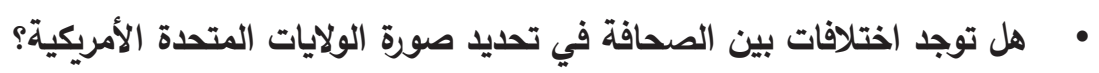

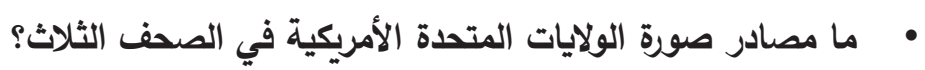

\section{ثانيا-خطوات تحديد المشكلة والصعوبات التي تواجهه.}

\section{أ-الإحساس بالمشكلة}

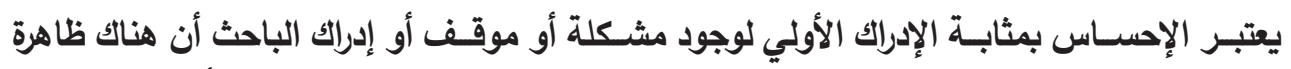

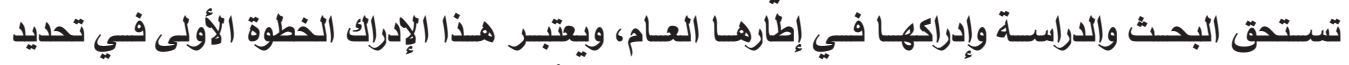

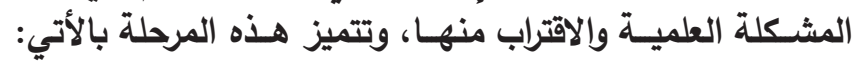

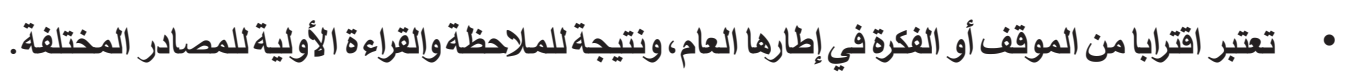
• عتبر دافعا لتطوير البحث والتقصي في المثكلة وبداية الطريق للتحديد النهائي. • تهيئة الباحـث لإعـادة النظر في المشكلة وبناء العلاقات بيـن عناصرها، والعلاقـات مع عناصر خارجية أخرى

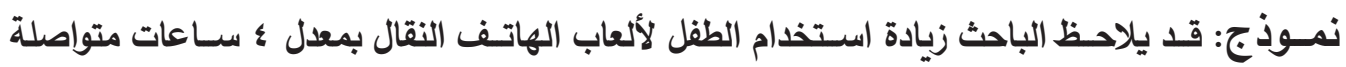

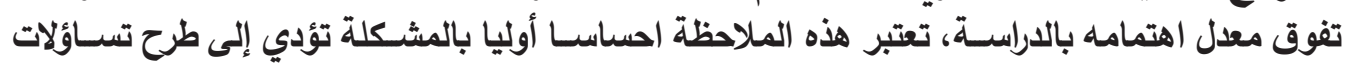

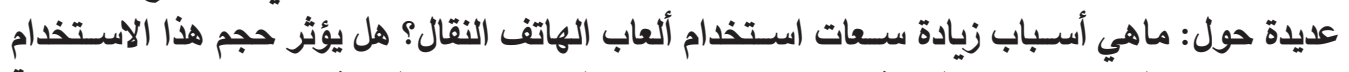

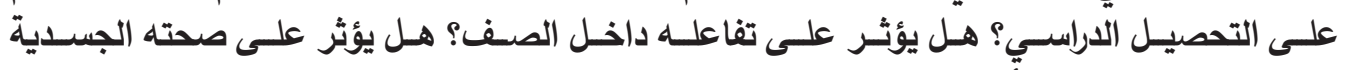

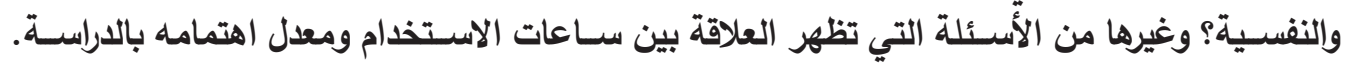

\section{ب- تحليل المشكلة العلمية}

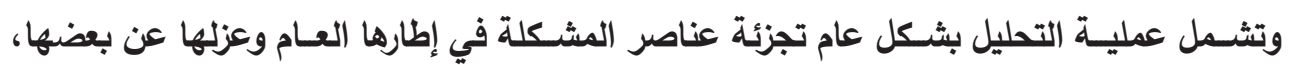

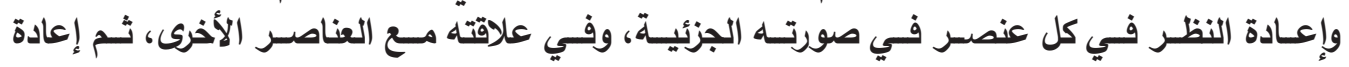

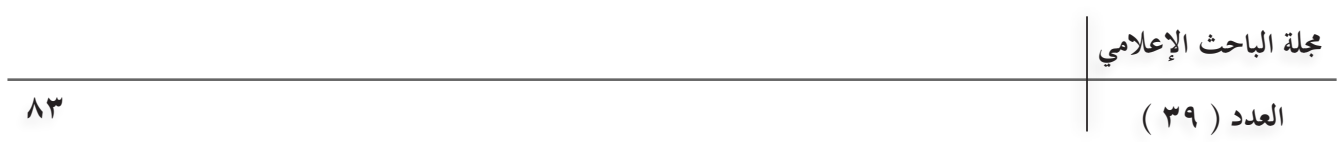


تركيـب هـذه العلاقـات مـرة أخرى في شـكلها النهائي القابـل للتطبيق. يقـوم الباحث في هـذه المرحلة

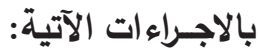

• عزل عناصر المشكلة والنظر إلى كل عنصر فيها في إطار جزئئ28.

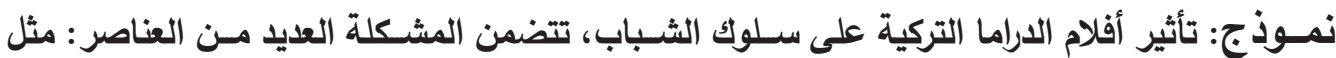

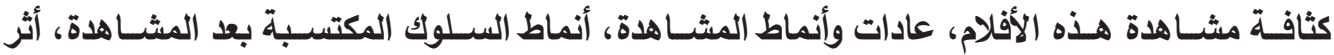

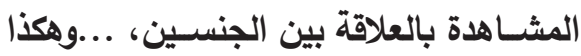

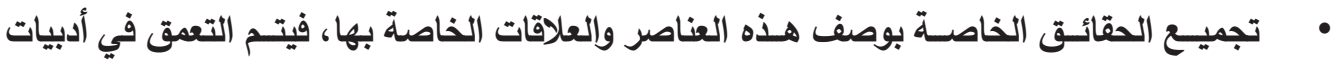

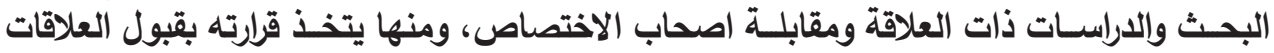

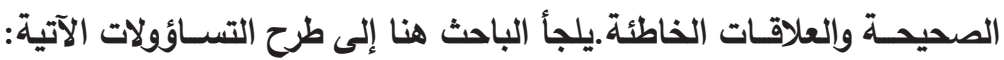
• هل هناك علاقة بين حجم المشاهدة وتغيير السلوك؟

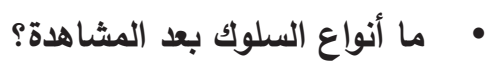

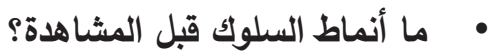
• هل تتلخل الأسرة لضبط أنواع السلوك الجديدة؟ ماهن ج- تقويم المشكلة العلمية

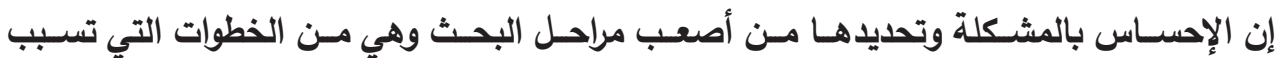

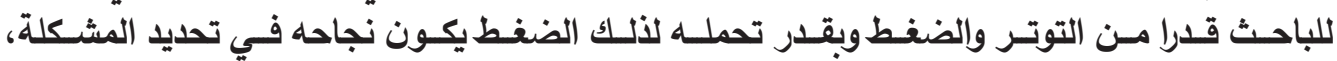

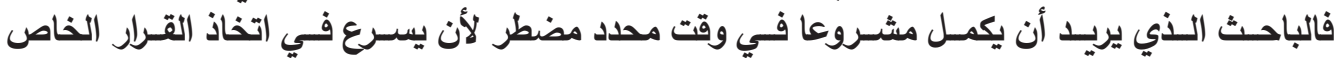

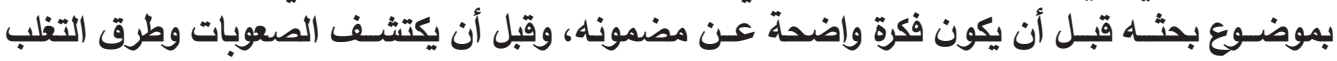

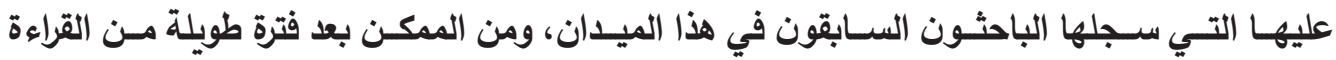

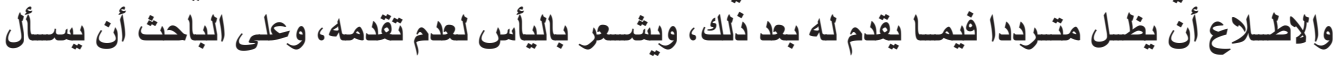

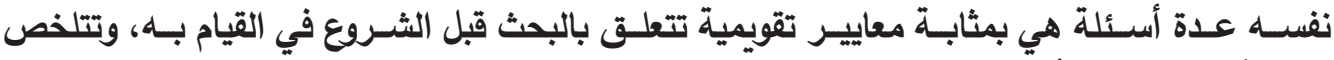
هذه الأسـئلة فيمـا يأتي: أسئي

هل تستحوذ المشكلة على اهتمامي ورغبتي؟ • هل ستضيف هذه المشكلة إلى المعرفة شيئا؟ الفئ

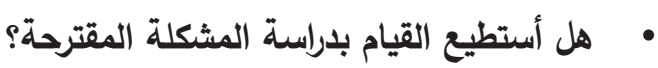

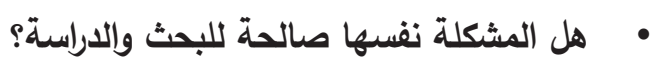

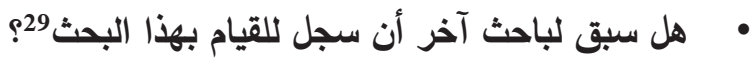

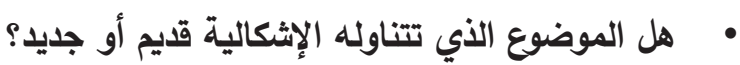


إلى أي مدى سوف يسهم حل المشكلة في خدمة المجتمع المغني بالدراسة؟

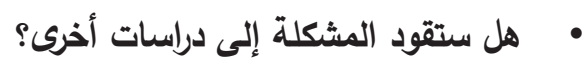

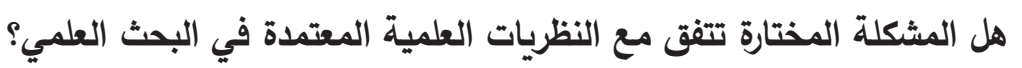

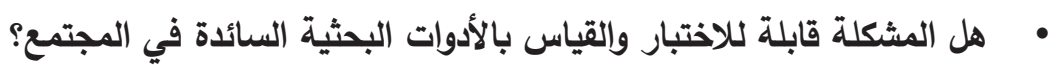

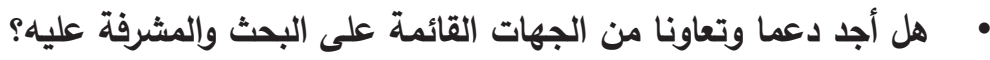

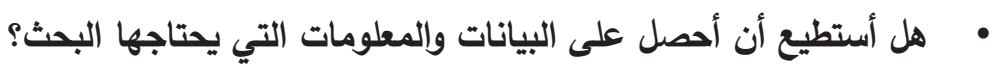

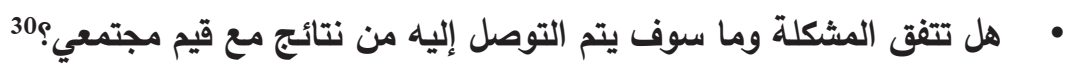
ومع هذه التساؤلات يمر الباحث بظروف ويواجه صعوبات يمكن تلخيصها في النقاط الآتية 31:

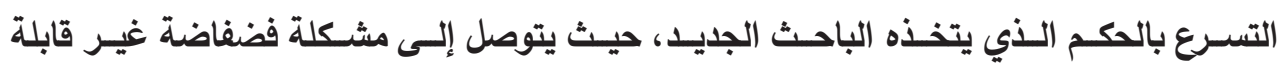

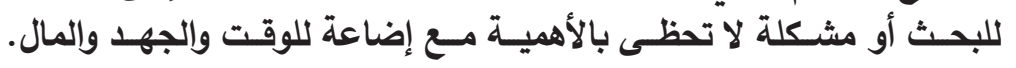

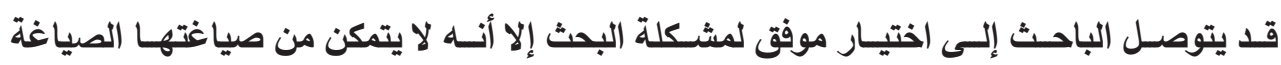

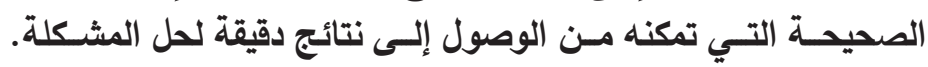

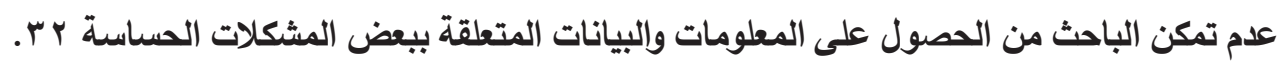

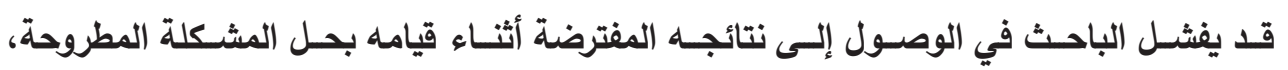

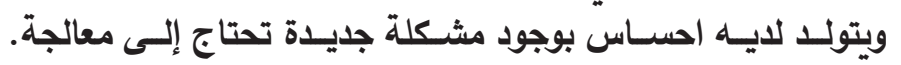

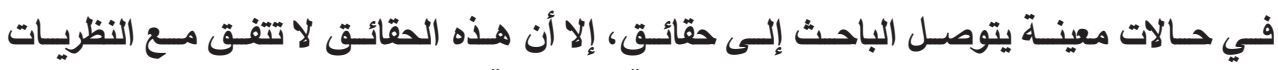

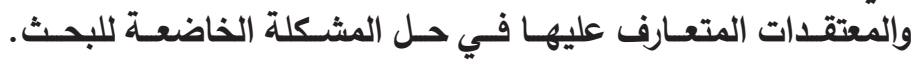

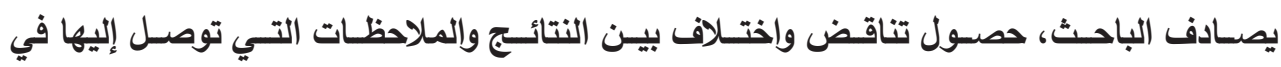

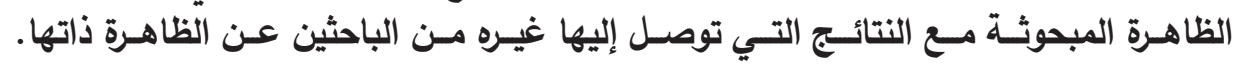

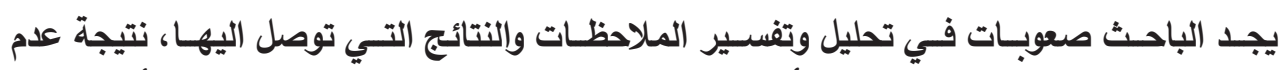

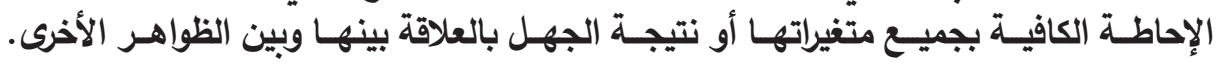

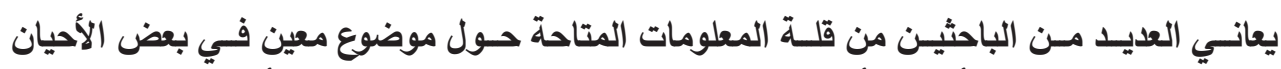

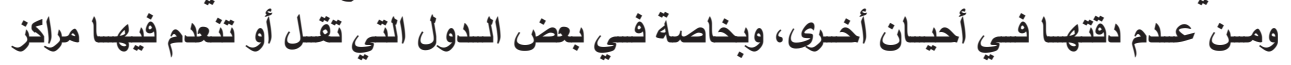
الأبحاث المتقدمة، والتقنيات المتطورة تسـاعد الباحثيّين في الحصول على معلى معلومات دقيقة وكافية.

\section{ثالثا: العوامل المؤثرة في اختيار المشكلة}

تطرق الكثير مـن الباحثين 33فـي مجال مناهج الباحـث العلمي إلى العوامل التـي تؤثر في اختيار

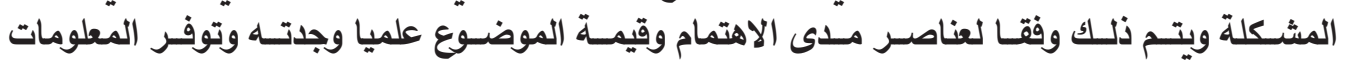

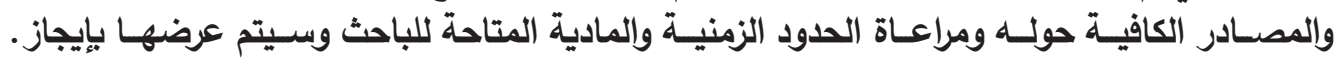




\section{ا- مدى الاهتمام بالمشكلة}

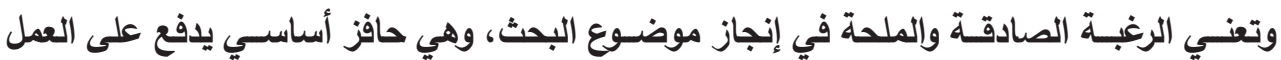

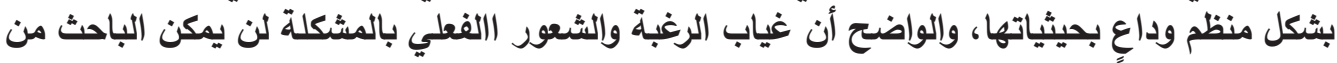

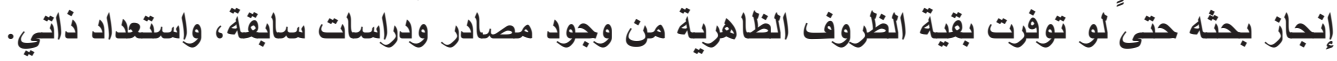
r- يكون الموضوع ذا قيمة وأهمية علمية

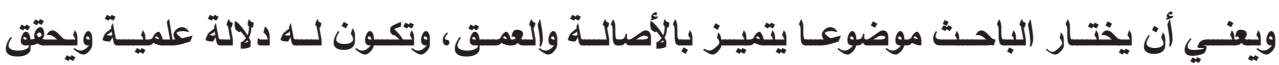

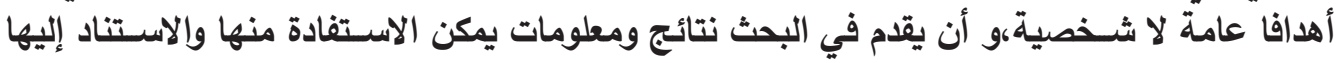

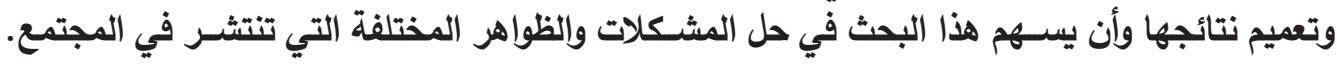

\section{ץ- جدة الموضوع وتجنب المحاكاة والتكرار}

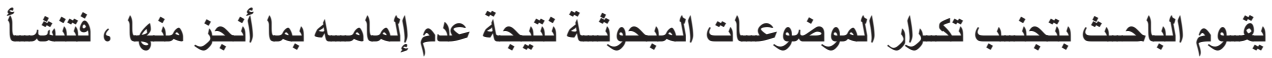

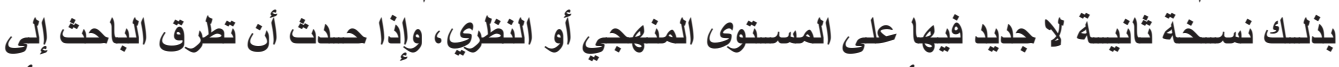

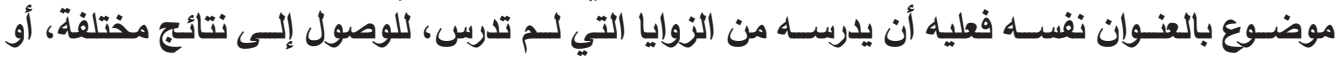

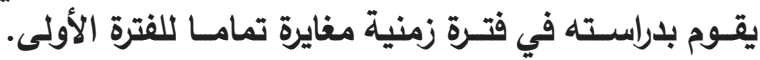

\section{؟- توفر المصادر الهامة والوثائق والبيانات المطلوبة}

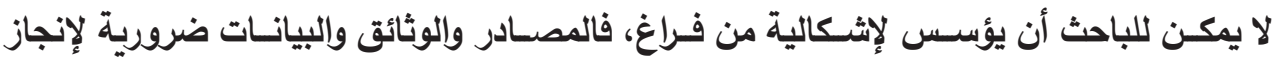

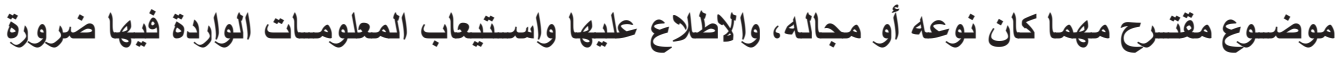
مهمة في عملية الإنجاز وكتابة الإثـكالية.

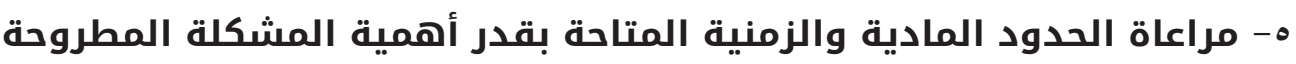

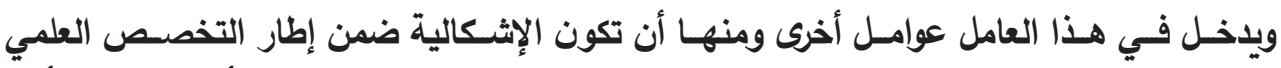

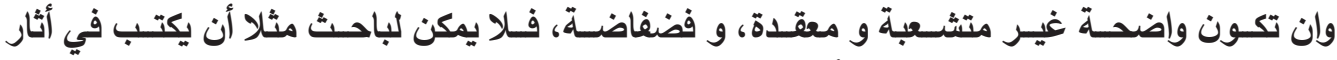

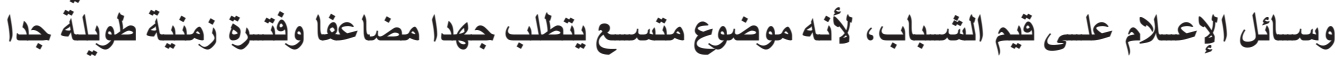

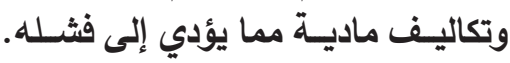

\section{צ- معرفة الصعوبات التي تحيط بالباحث والبحث بوله}

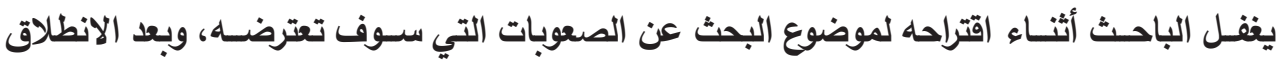

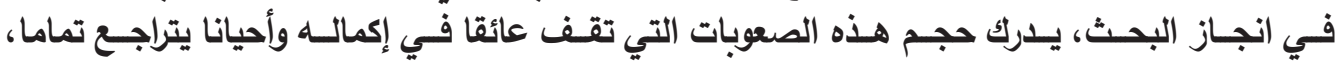
وعليـه فـإن دراســة الصعوبات وتوقعها من طرف الباحـث مهمة جدا في اختيار نوع البحث ومشـكلته.

\section{رابعا: خصائص المشكلة القابلة للبحث}

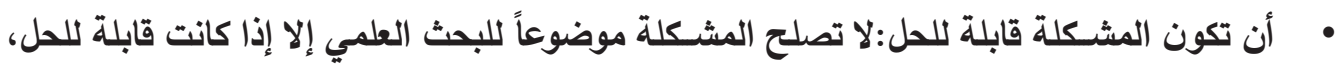

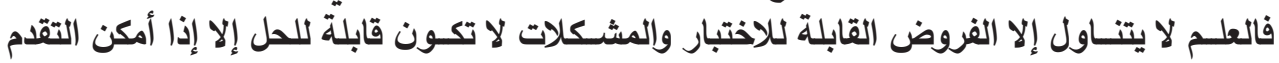


بفـرض قابـل للاختبـار كحل مبائسي لها 34.والمشـكلات التي تتناول مســائل فلسـفية أو أخلاقية

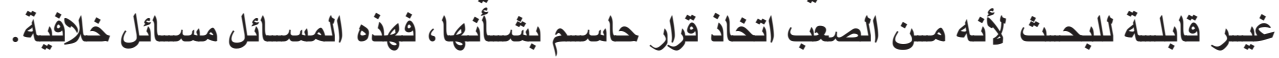

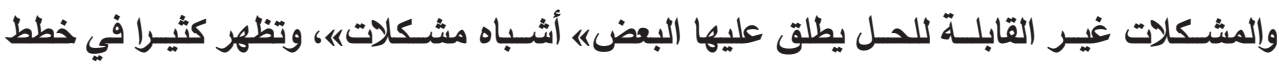

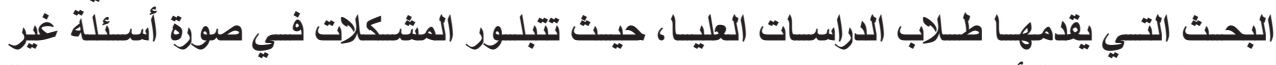

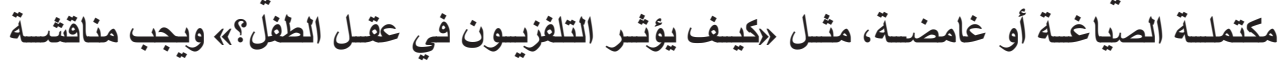

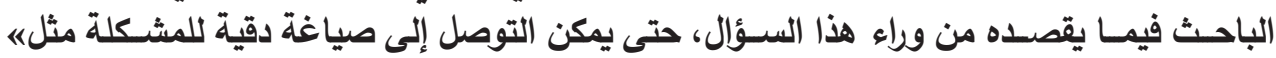

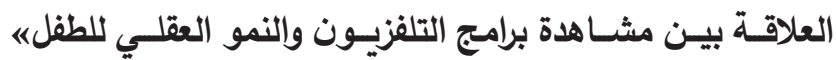

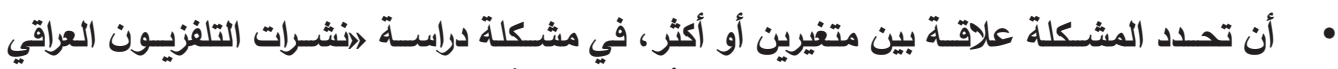

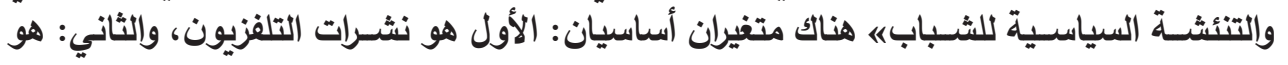
التشــئة السياسية للمراهقين.

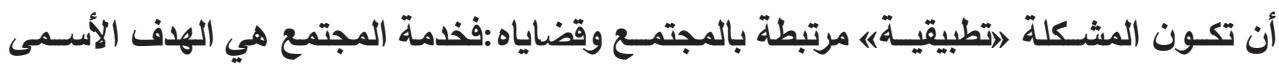

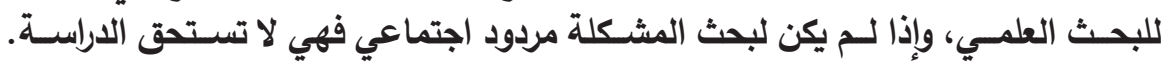

\section{خامسا: اعتبارات مهمة عند اختيار المشكلة}

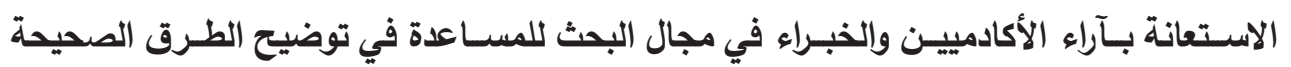

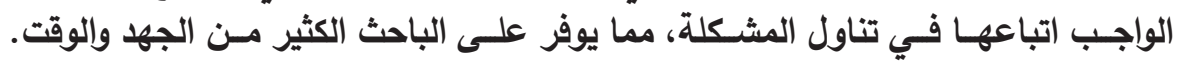

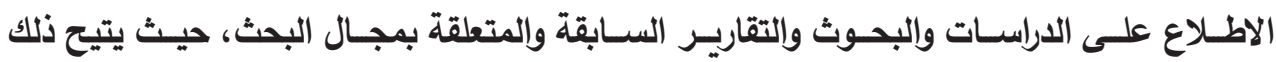

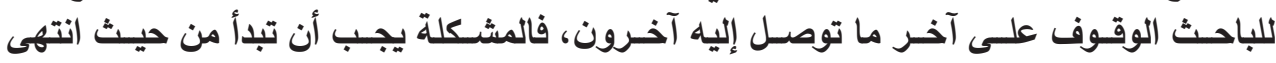

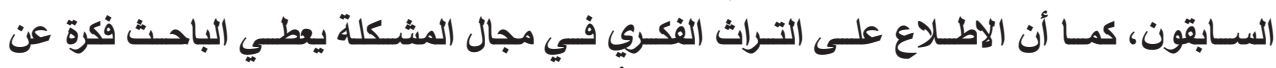

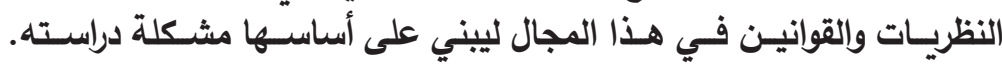

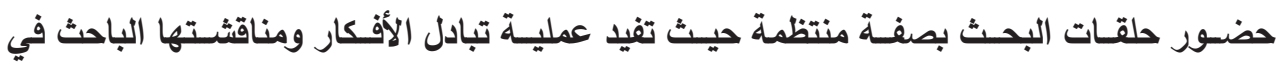

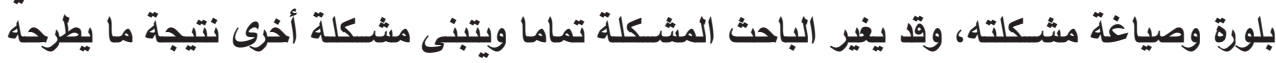

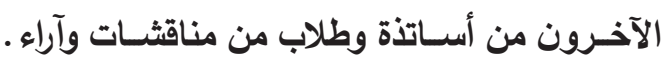

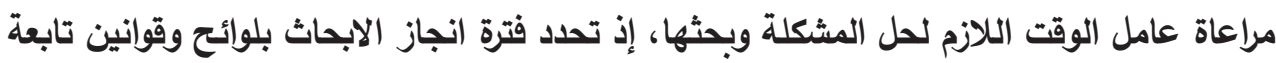

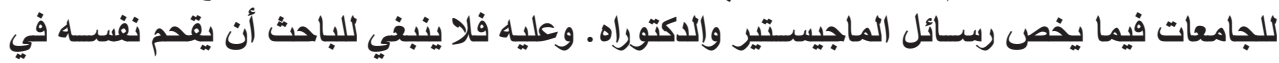

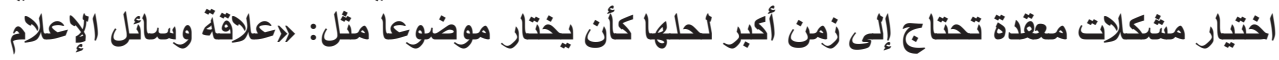

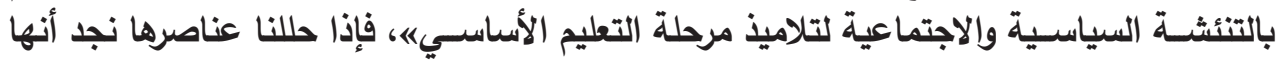

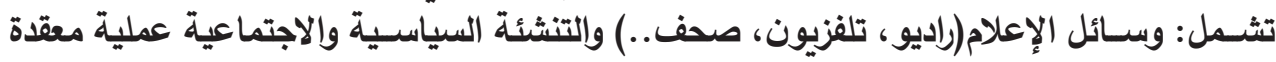

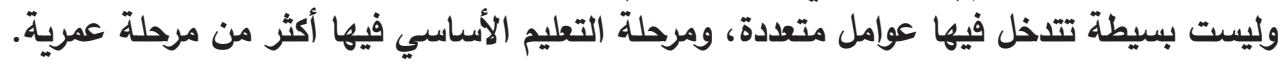

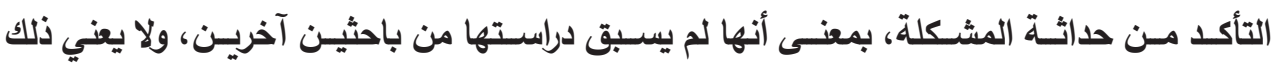

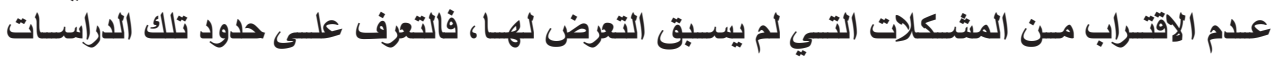

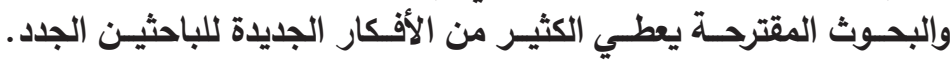


معرفـة الصعوبـات الاجتماعيـة والاقتصاديـة والسياسـية التـي يمكن أن تحيـط بمثـكلة البحث،

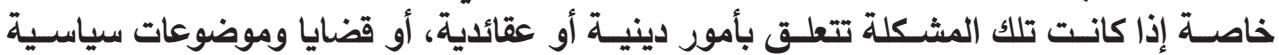

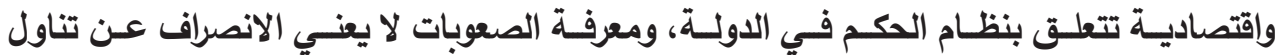

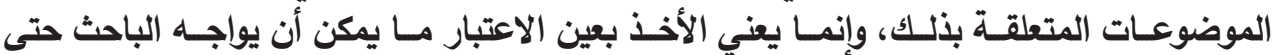

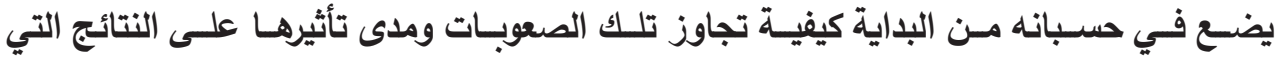
سـيتم التوصـل إليها، خاصــة إمكانية تعميـم النتائج.

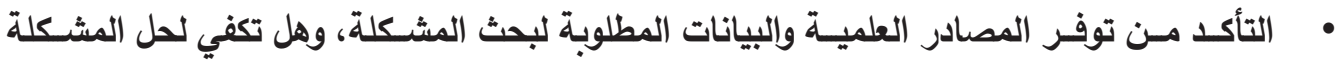

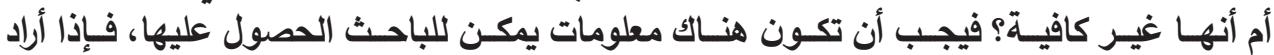

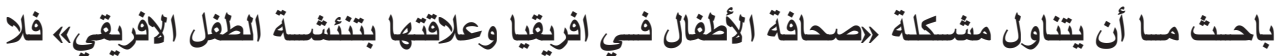

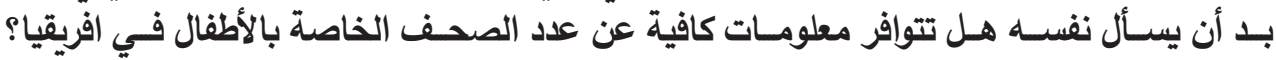

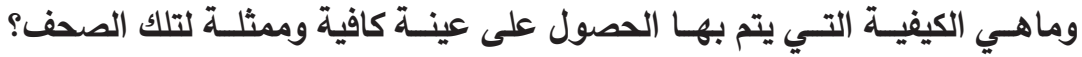

\section{سادسا: مصادر الحصول على موضوع المشكلة}

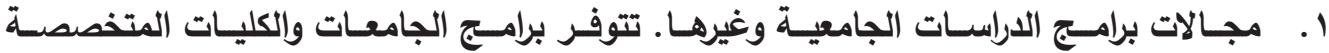

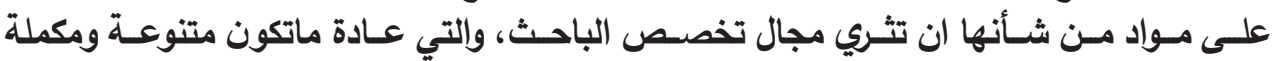

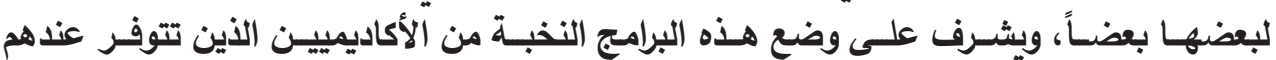

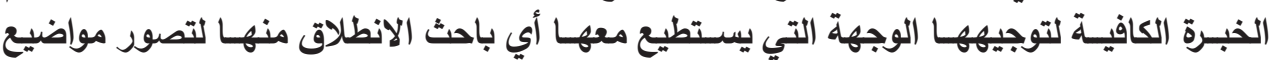

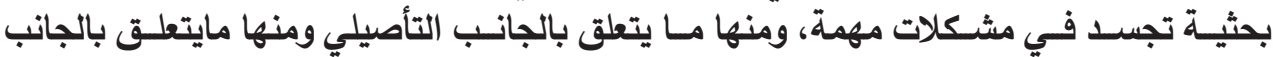

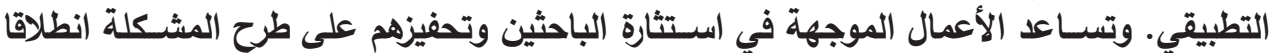

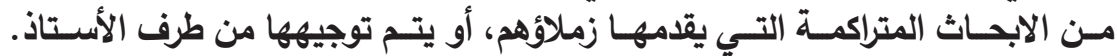

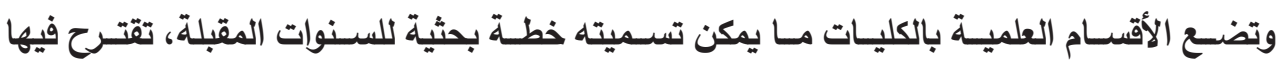

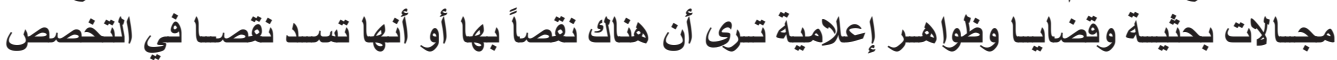

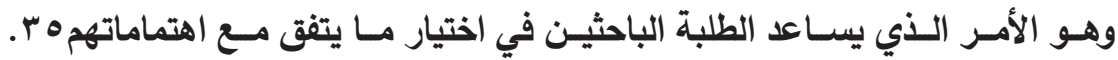

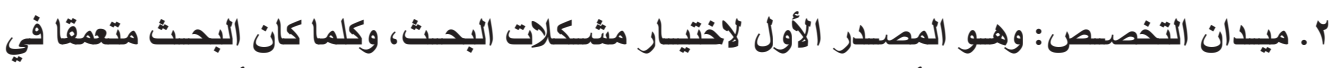

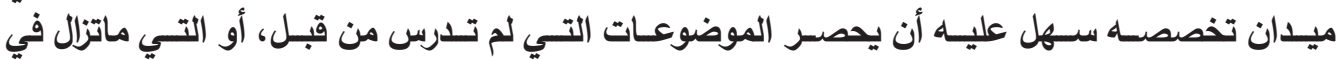

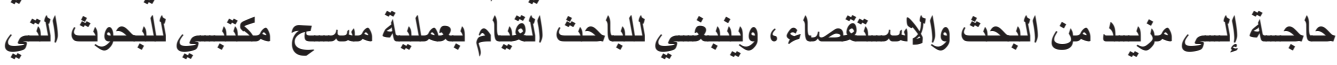

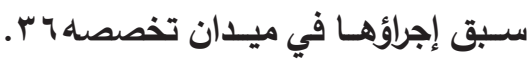

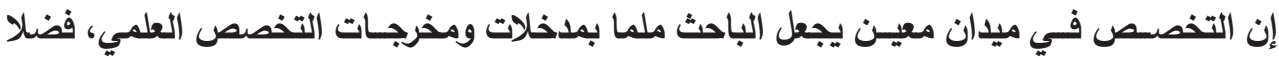

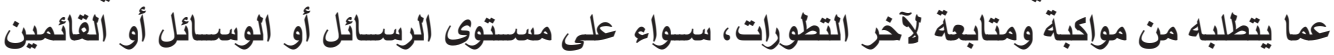

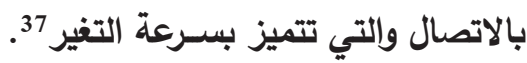

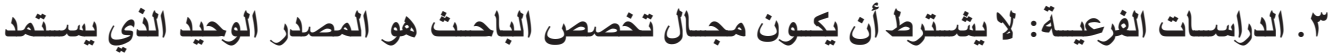

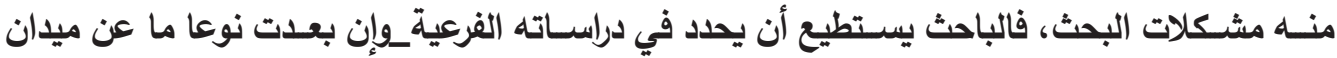

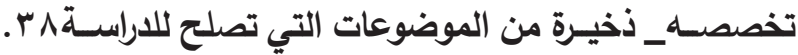




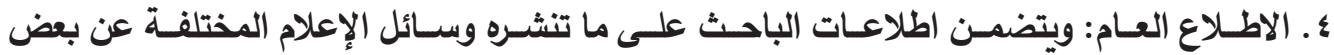

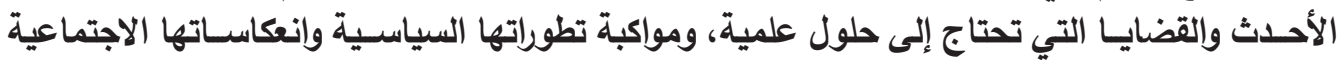

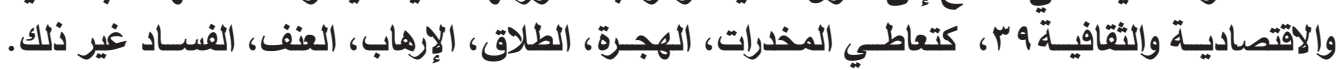

\section{ه- القراءة الدقيقة في ميدان البحث كئهئ}

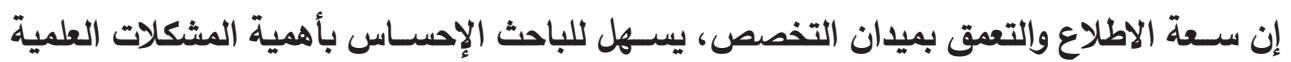

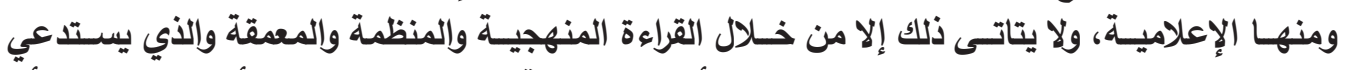

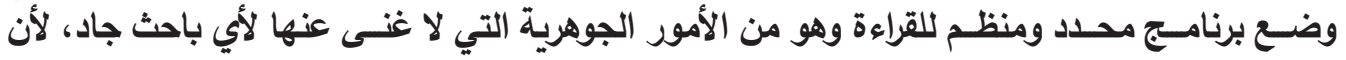

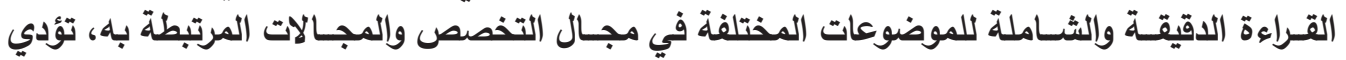

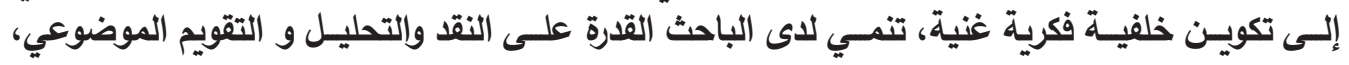

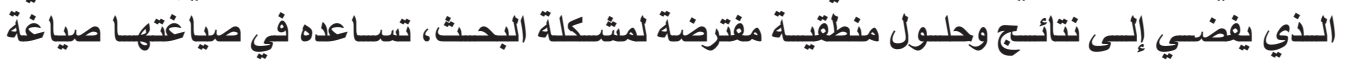

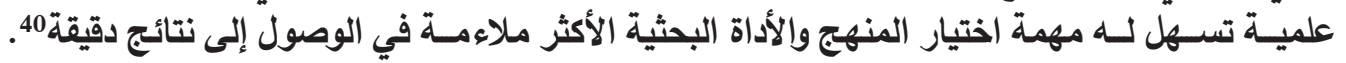

ج-الدراسات السابقة

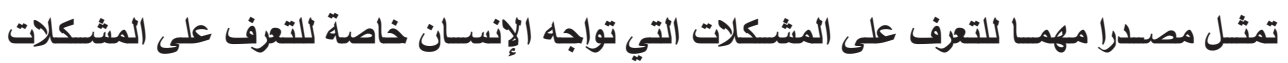

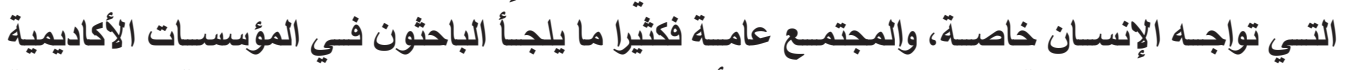

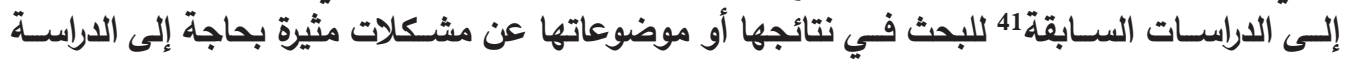

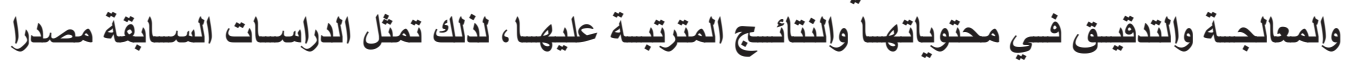

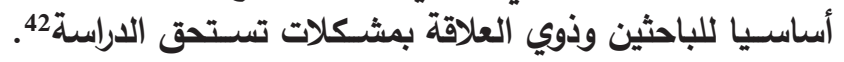
وتساعد الاراسات السابقة الباحث من حيث • • بلورة مشكلة البحث التي يعمل على إنجازها.

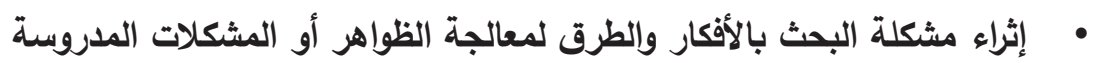

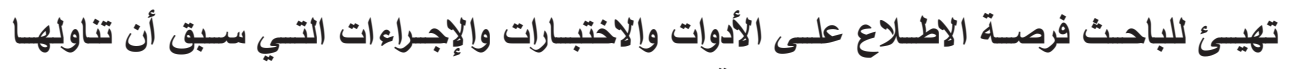

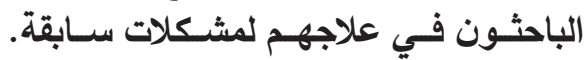

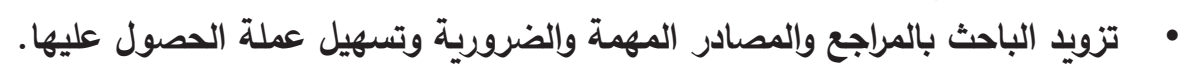

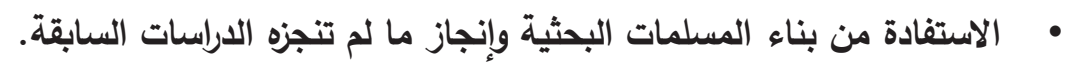

\section{v- الملاحظة العلمية}

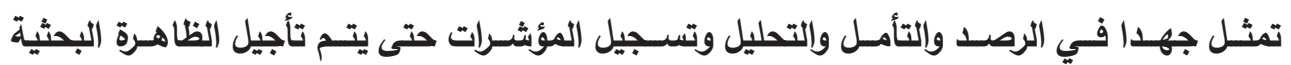

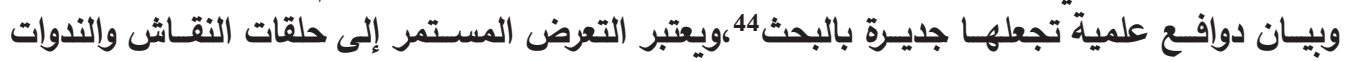

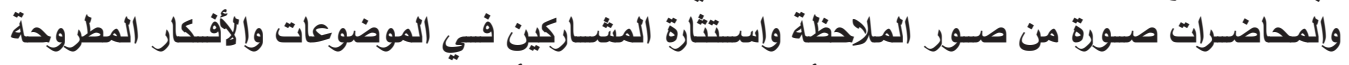

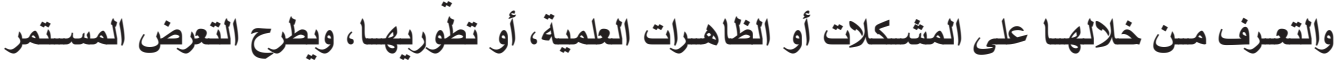

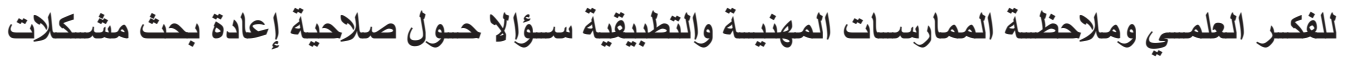


علميـة سـبق دراسـتها وإنتهى آخـرون إلى نتائــج وتعميمات خاصــة بها5

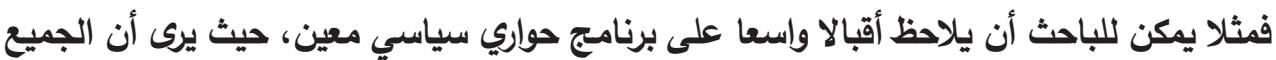

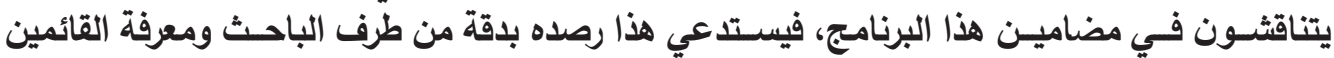

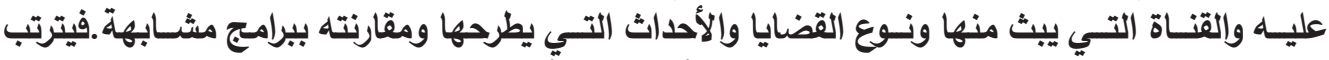

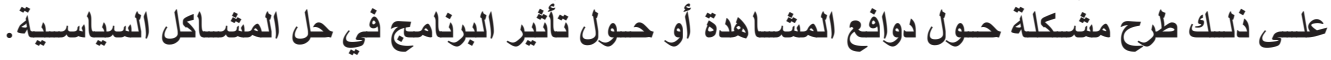

$$
\text { ويحصر باحثون آخرون أنواعاً أخرى للمصادر في: }
$$

1. المصدر الثخصي المتمثل في خبرات الباحث وإعداده العلمي.

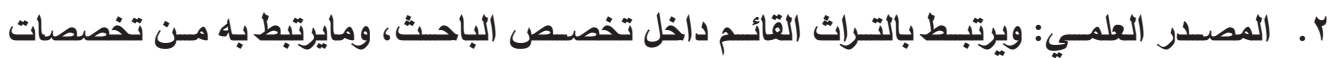

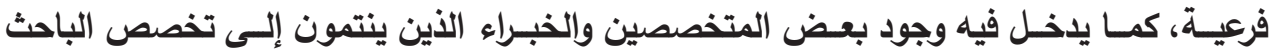

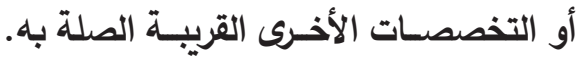

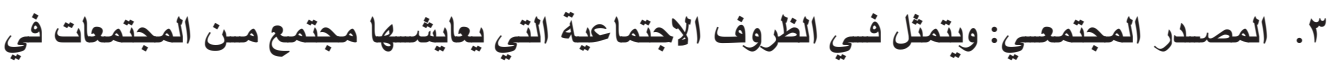
مرحلة معينـة من تاريخه.

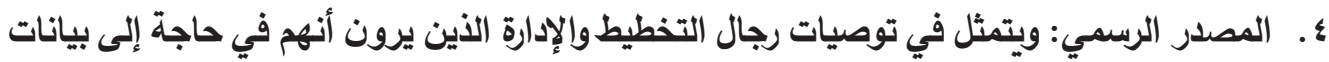

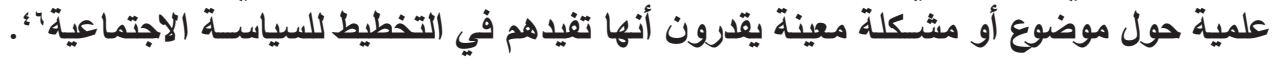

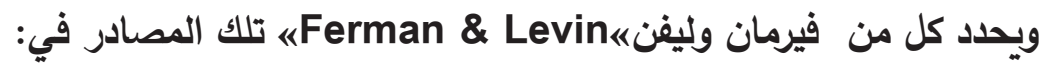

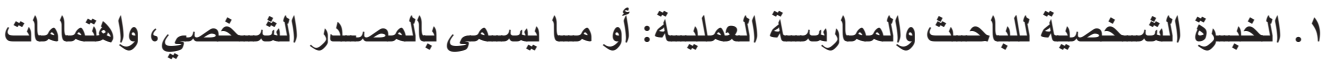

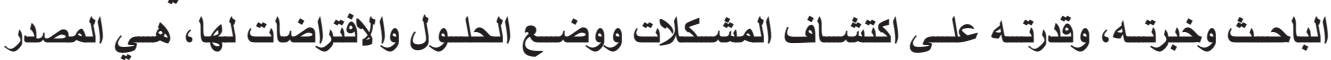

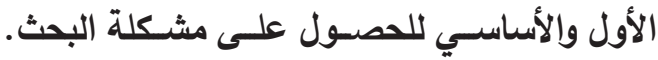

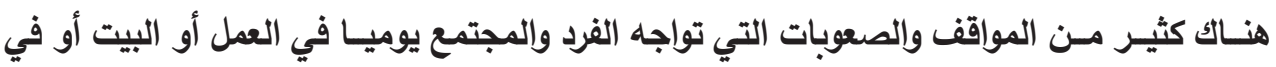

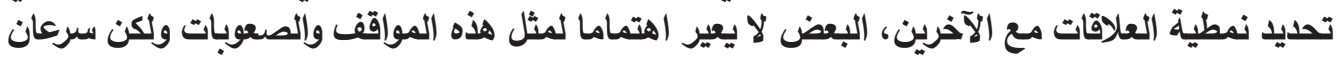

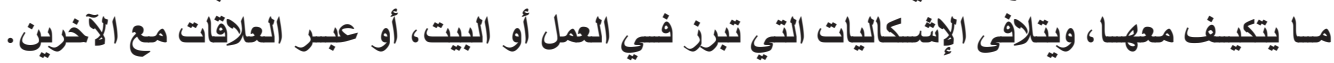

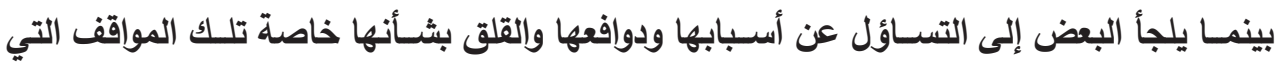
تمثـل تعليـا على كل أو بعض البـ القيم وإلمعايير الاجتماعيـة أو الاعتقادية، أو الاتصالية.

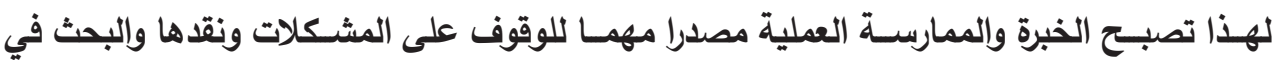

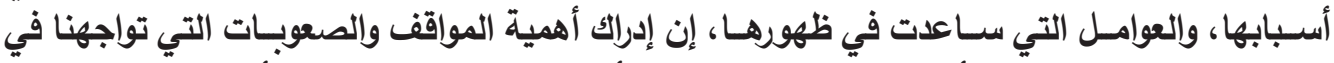

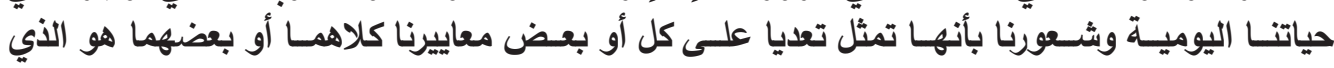

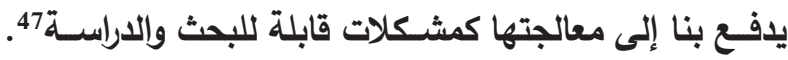

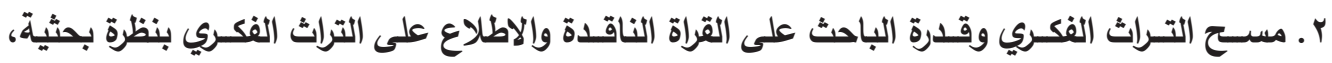

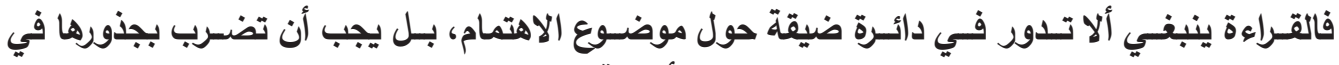

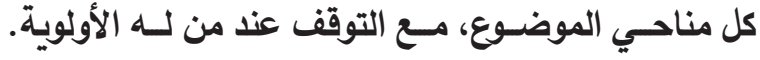




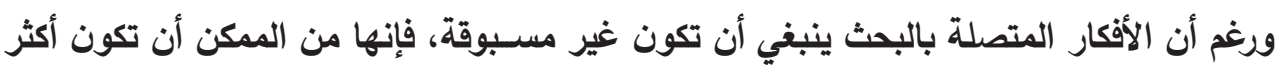

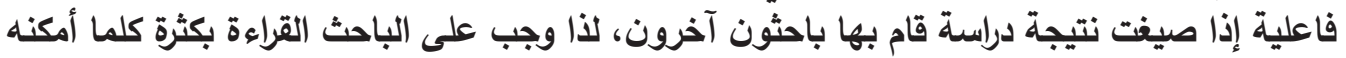

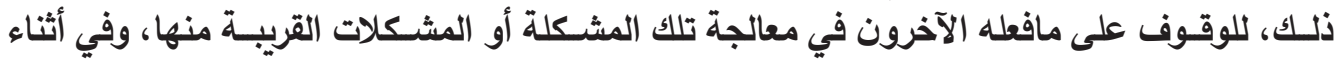

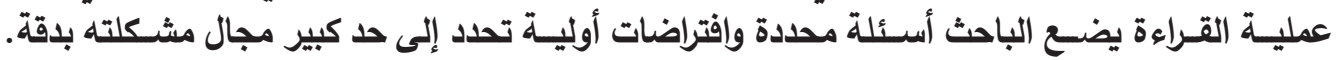

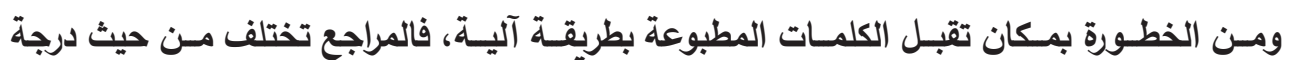

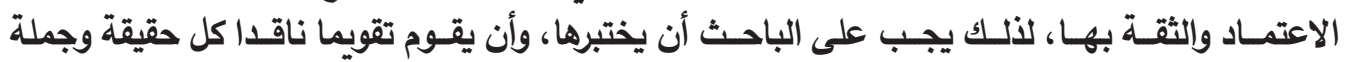

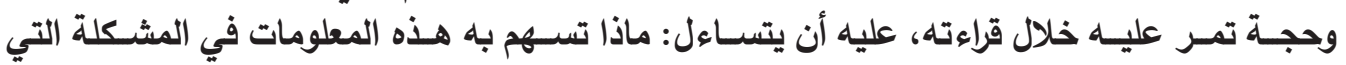

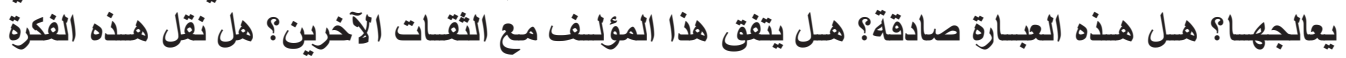

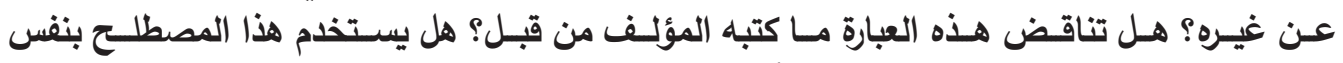

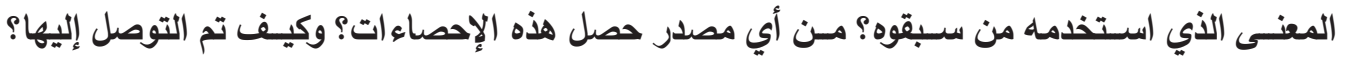

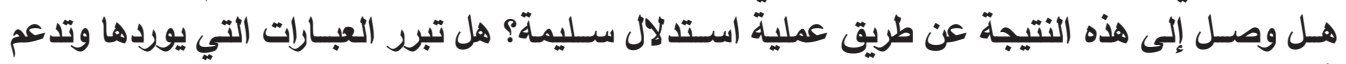
رأيـهـ فـي النتائج التي توصـل هذه إليها؟.

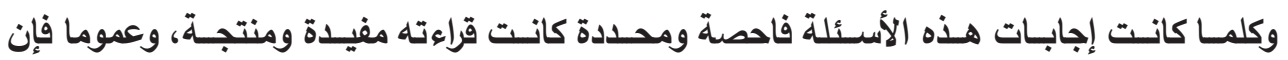

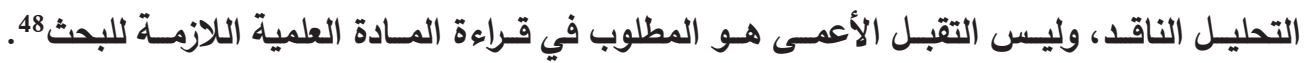

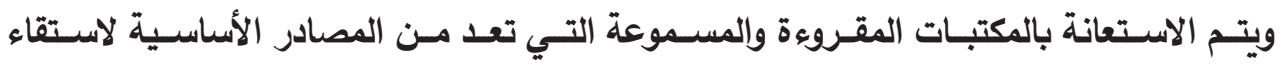

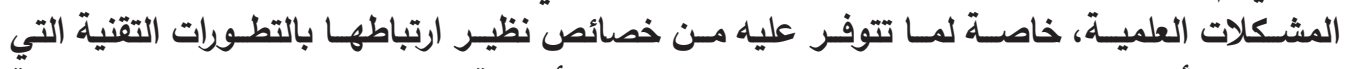

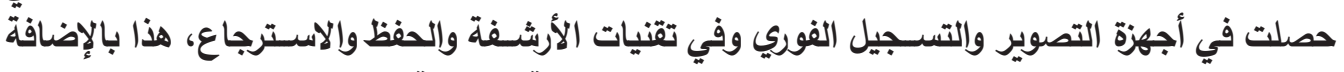

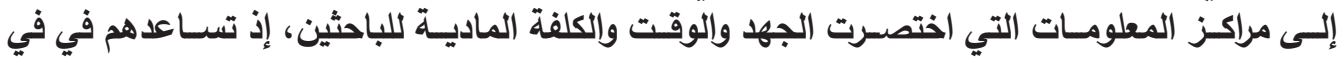

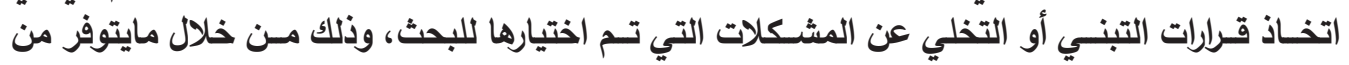

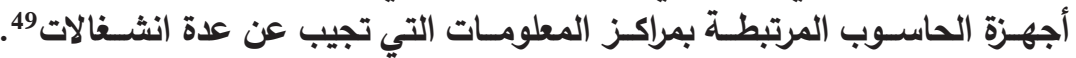

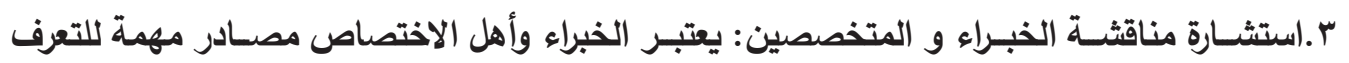

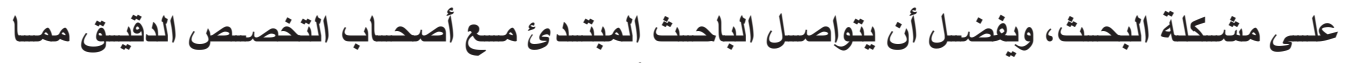

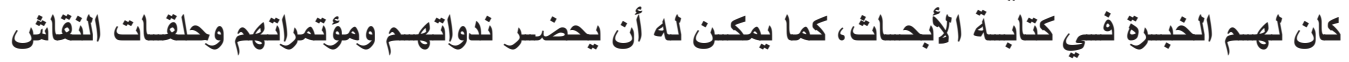

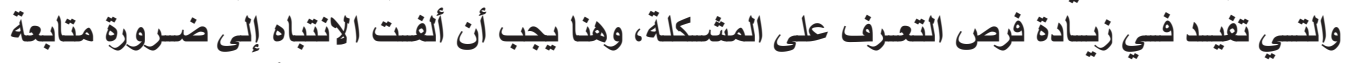

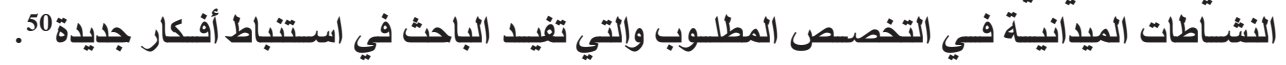
سابعا:خصائص متعلقة بالباحث والبحث في تحديد الإشكالية

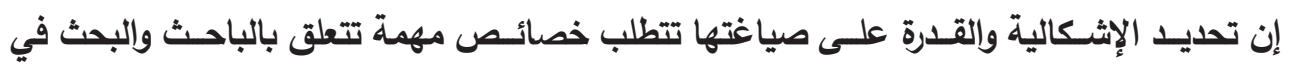

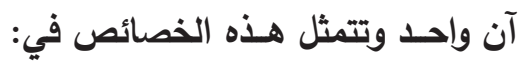

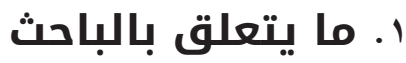
أ. المعيار الأتي لاختيار الموضوع، ويعبر عن مدى قدرة الباحث في الإحاطة بموضوعه وإستعابه، ويقصدبه:

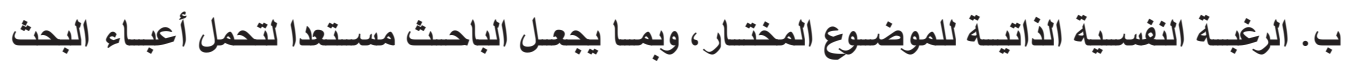




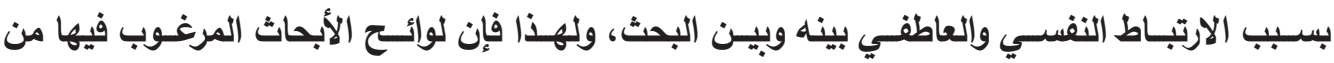

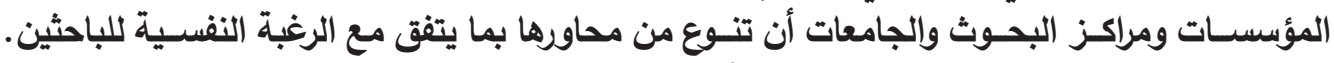

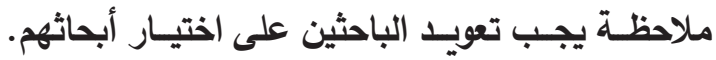

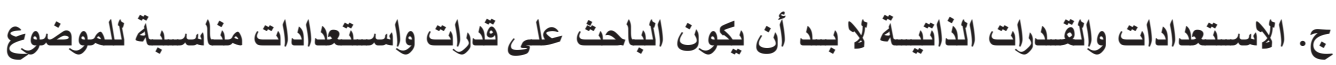

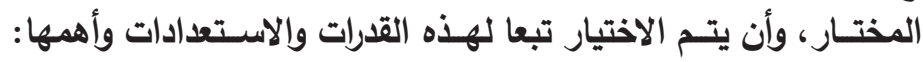

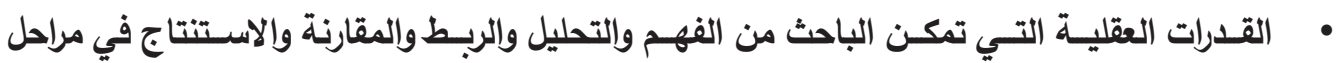

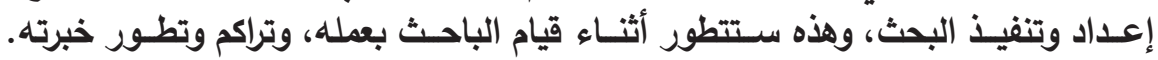

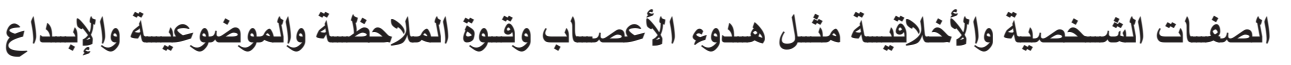

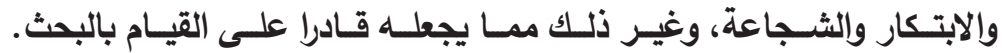

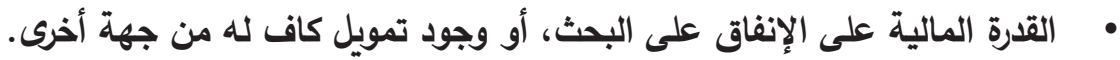

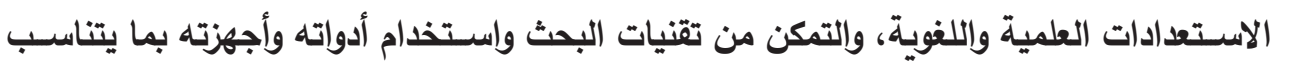

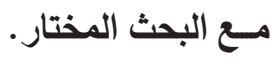
توافر الوقت الكافي لإعداد وتنفيذ البحث. • • الخبرة العلمية والمهنية اللازمتان للبحث. r.r.خصائص تتعلق بموضوع البحث: • • المعيار الموضوعي، وهو ما يجب ان يتوفر في الموضوع ذاته.

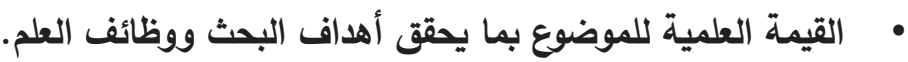

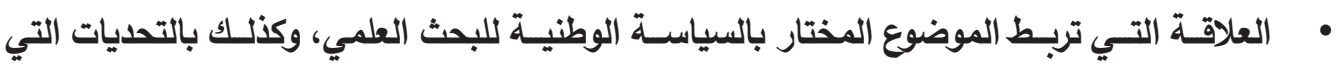
تطرحها الحياة المعاصـرة واحتياجاتها.

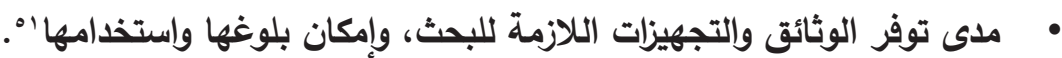

خاتمة

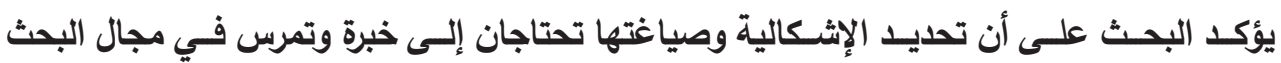

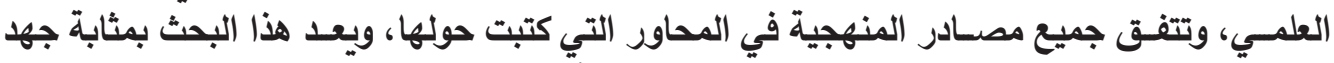

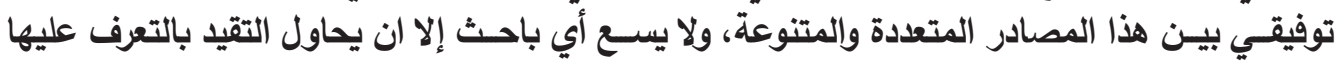

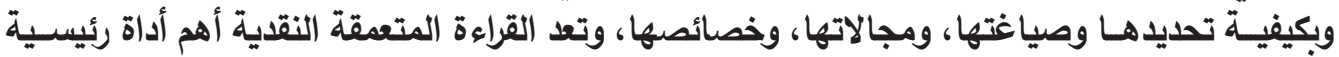

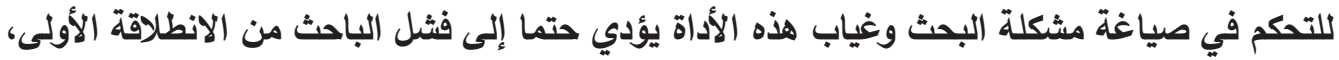

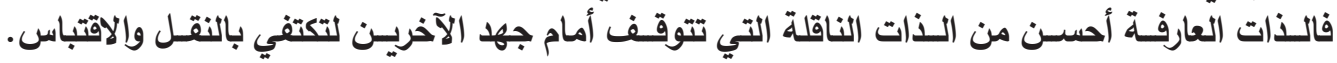

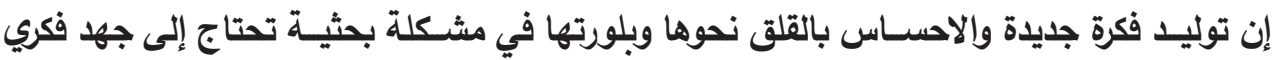

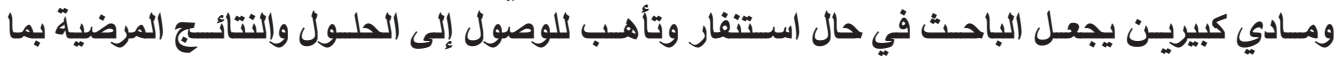

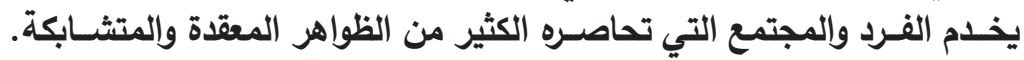




\section{الهوامش}

1. . محمد عبد الحميد: البحث العلمي في الاراسات الإعلامية، القاهرة، عالم الكتب، . . . Y، ص 79.

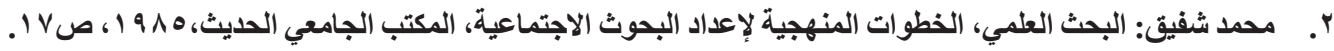

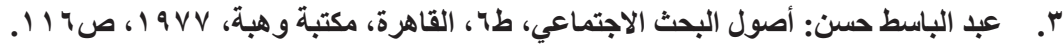

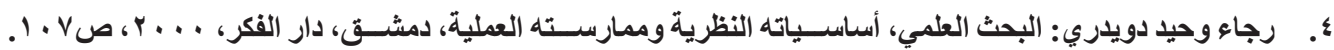

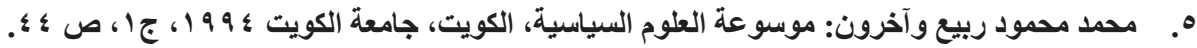

.Lilian Rippel, Problem Identification and Formulation, N.Y, 1975 . .

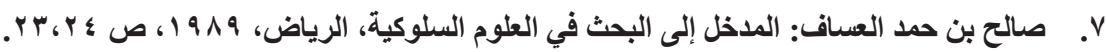

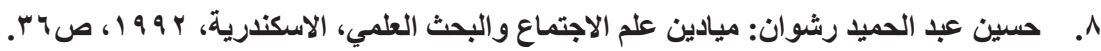

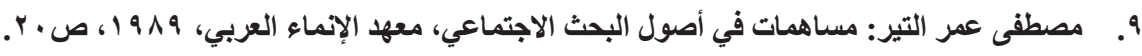

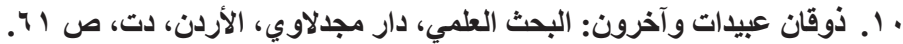
ا با

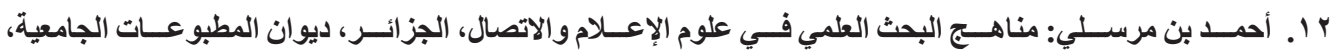

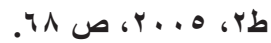

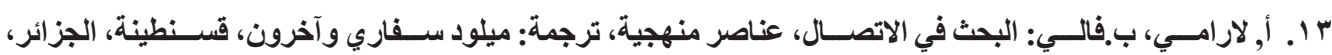

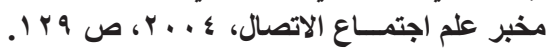

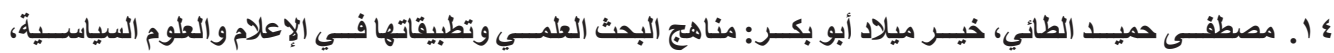

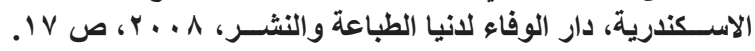

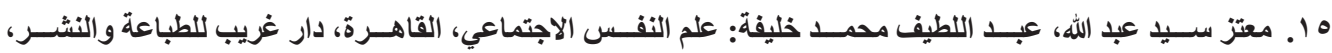
دا

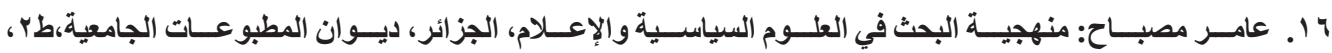
.

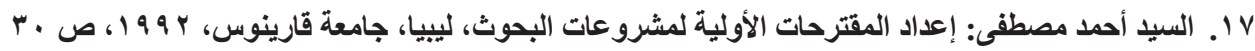

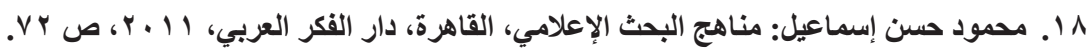

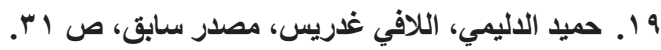

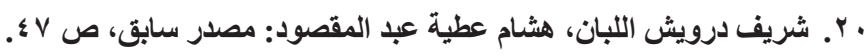

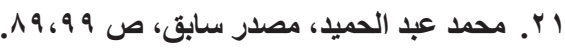

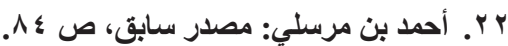

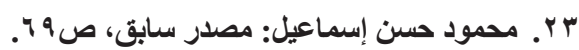

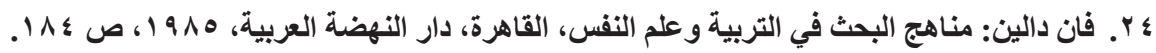

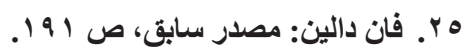

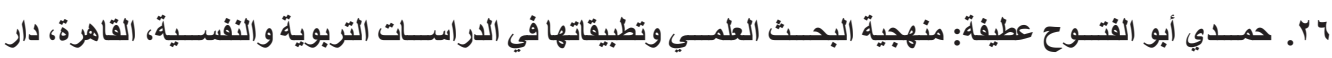

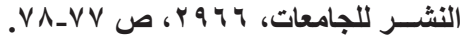

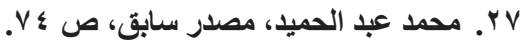




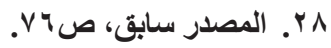

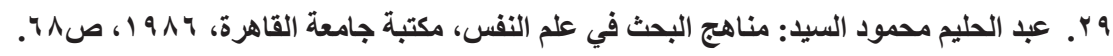

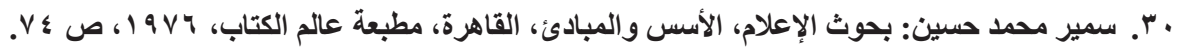

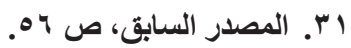

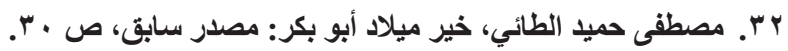

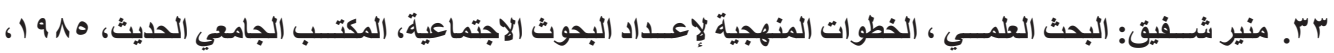

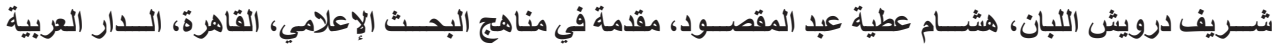

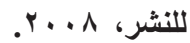

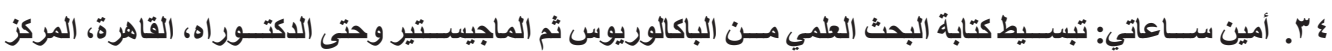

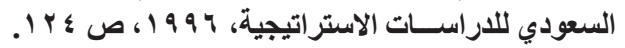

ه م. شـريف درويش اللبان، هشــام عطية عبد المقصــود: مقدمة في مناهج البحــث الإعلامي، القاهرة، الــدار العربية

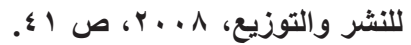

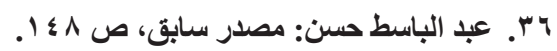
V V

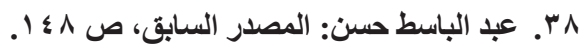

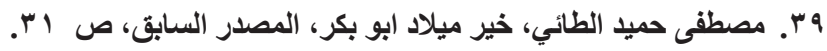

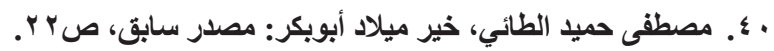

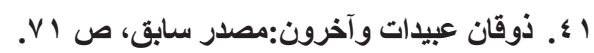

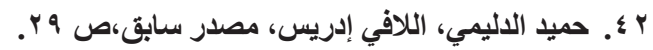

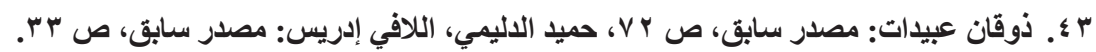
ع ـ شريف درويش اللبان، هشام عطية عبد المقصود:مصدر سابق، ص م . ؛.

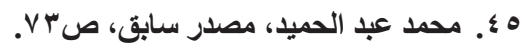

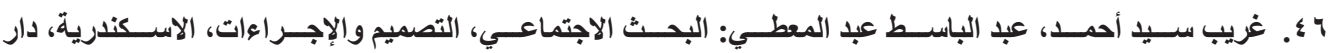

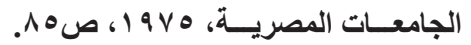

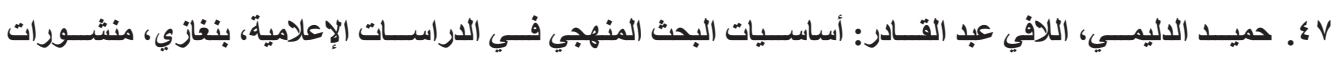

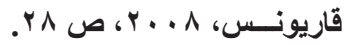

Gerald Ferman and Jack Levin; Social Science Reseach, A hand book for students, . $\leqslant \wedge$ $V_{-} P^{\circ} .19 \vee \cdot$.jhonwiely and sons

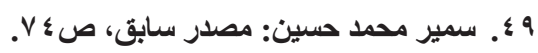
••.

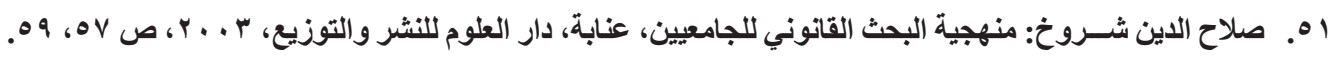

